"A FEA e a USP respeitam os direitos autorais deste trabalho. Nós acreditamos que a melhor proteção contra o uso ilegítimo deste texto é a publicação online. Além de preservar o conteúdo motiva-nos oferecer à sociedade o conhecimento produzido no âmbito da universidade pública e dar publicidade ao esforço do pesquisador. Entretanto, caso não seja do interesse do autor manter o documento online, pedimos compreensão em relação à iniciativa e o contato pelo e-mail bibfea@usp.br para que possamos tomar as providências cabíveis (remoção da tese ou dissertação da BDTD)." 


\section{UM MODELO DE EXPECTATIVAS RACIONAIS}

\section{PARA CRASHES}

\section{Aluna: Ana Paula Neves Granieri Domenici}

Dissertação apresentada à Faculdade de Economia, Administração e Contabilidade e ao Instituto de Matemática e Estatística da Universidade de São Paulo para obtenção do Título de Mestre.

Orientador: Prof. Dr. Gerson Francisco

São Pauio

2002 
Ao meu lindo Beto 


\section{SUMÅRIO}

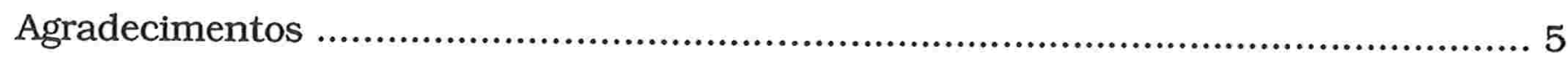

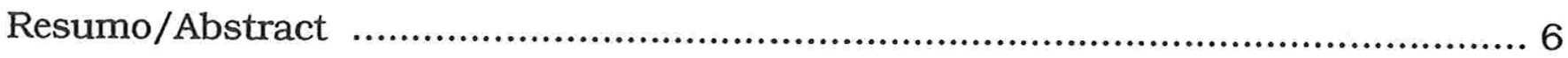

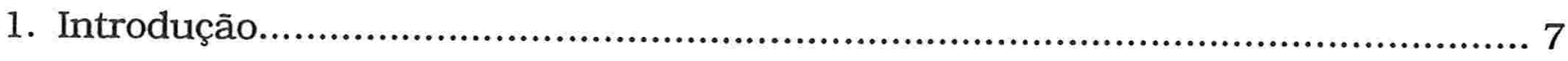

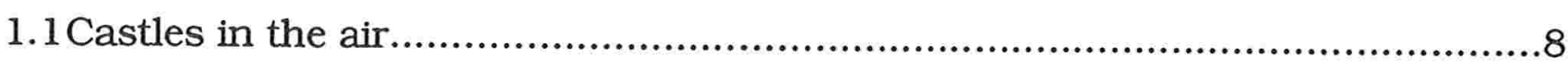

1.2 Escopo deste trabalho............................................................ 10

2. O Modelo............................................................................... 13

2.1 Dinâmica de preços............................................................. 14

2.2 O Crash .............................................................................. 16

2.3 Modelo Macroscópico.................................................................... 17

2.4 Modelo Microscópico................................................................20

2.5 Redes de interação...............................................................22

2.5.1 Posicionamento bi-dimensional..............................................22

2.5.2 Hierarchical Diamond Lattice ....................................................25

2.6 Generalização.......................................................................27

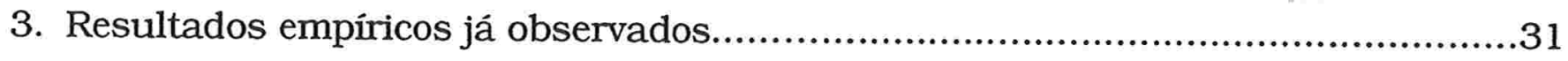

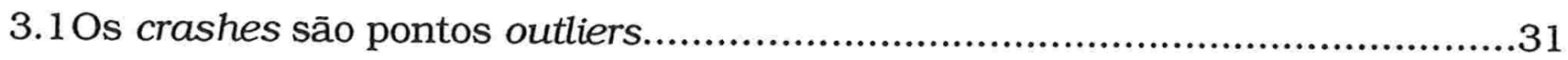

3.2 Ajuste do modelo para o mercado de ações...........................................33

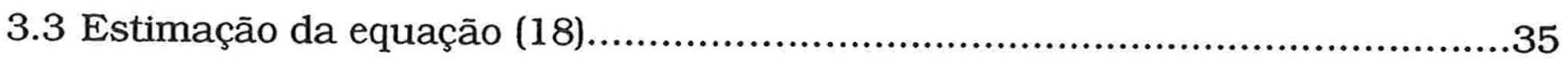

3.4 Estimação da equação (22) .......................................................35

4. Aplicação ao mercado brasileiro...........................................................37

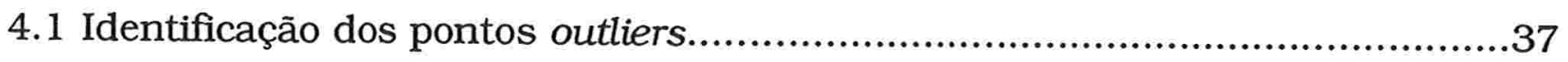

4.2 Estimação dos parâmetros usando a equação (18)..................................40

4.2 .1 Crise asiática..............................................................41

4.2 .2 Crise russa................................................................42

4.2.3 Crise desvalorização do Real................................................43

5. Previsibilidade ............................................................................46

5.1 Alarmes Falsos.................................................................

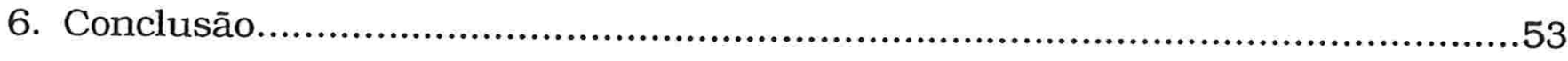

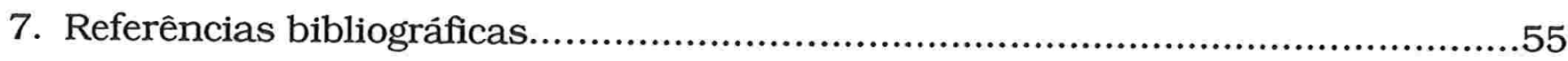




\section{AGRADECIMENTOS}

São muitas as pessoas que merecem meu agradecimento por terem, não só contribuído tecnicamente, mas também me incentivado e me apoiado para que esta dissertação fosse concluída.

Especial agradecimento ao BankBoston pelo investimento e confiança.

À minha familia e amigos, pelas ausências em momentos tão importantes. Prometo recuperá-los o mais breve possivel.

Agradeço carinhosamente aos meus pais. Que esse trabalho represente, se isso for possivel, todo o investimento e preocupação dedicados à minha formação.

Agradeço também a todos os professores, coordenadores e funcionários, especialmente ao Prof. Henrique Von Dreifus, pelas horas de dedicação e preocupação com a qualidade do nosso curso ao longo desses dois anos.

Especiais agradecimentos ao meu professor Amaury Fonseca Júnior, que não pôde ser meu orientador devido a fatores burocráticos, agradeço pela assistência teórica e pelas nossas horas de discussão.

$\mathrm{E}$, finalmente, minha enorme gratidão aos meus orientadores Gerson Francisco e Rogério Rosenfeld, pelo suporte técnico e acadêmico e, especialmente, pela enorme paciência dedicada. A colaboração de vocês foi decisiva para a elaboração dessa dissertação. 


\section{RESUMO}

Este estudo apresenta um modelo de expectativas racionais para bolhas e crashes. O modelo possui duas premissas básicas: 1) os grandes crashes são causados pela tendência que existe entre os traders à imitação das ações de seus vizinhos. Esse processo cresce até um ponto em que todos estão praticando a mesma ordem de venda e o sistema colapsa, causando os crashes. 2) uma hipótese que, já que os crashes não são pontos determinísticos, ainda é racional para os traders manterem seus investimentos, motivados pelas altas taxas de retorno causadas pelo crescimento das bolhas especulativas e correr o risco de um crash.

O final de uma bolha não é necessariamente o início de um crash, embora seja seu momento mais provável. Existe ainda uma probabilidade finita de ocorrer o final de uma bolha sem que o crash ocorra. O modelo apresenta previsões específicas sobre a presença de movimentos log-periódicos na formação de preços em períodos que antecedem os crashes. Analisamos também evidências empíricas observadas no mercado norte-americano e testamos as hipóteses para o mercado acionário brasileiro durante a década de 90 .

\section{ABSTRACT}

A rational expectation model for bubbles and crashes is studied. This model has two basic assumptions: 1) The big crashes are caused by local imitation between traders. This process grows up to a certain time when all traders are placing the same sell order at the same moment and the system goes into a collapse, causing a crash. 2) The hypothesis that, once the crashes are not deterministic points, it is still rational for the traders to keep their investments provided that they are compensated by higher spreads caused by the growth of the speculative bubble and taking the risk of the crash.

The end of a bubble is not necessarily the beginning of a crash, even though it is the most probable time. There is a finite probability of ending a bubble without having a crash. The model has specific predictions about a critical log-periodic patterns in pre-crash prices. Finally, we test the model for Brazilian markets in the 90's based on empirical evidences observed in US stock markets 


\section{1.) INTRODUCÃO}

Os crashes são eventos financeiros momentâneos que têm atraído a atenção de muitos acadêmicos e praticantes do mercado

A história das bolhas financeiras e dos crashes tem se repetido através dos séculos nos mais variados lugares desde a famosa bolha dos bulbos de Tulipa em 1636 em Amsterdā. O curioso é que, desde então, todas elas ocorreram sem nenhuma alteração em suas principais características:

1. As bolhas financeiras começam com um aumento na demanda que contraria as previsões mais otimistas do mercado;

2. Grandes retornos potenciais fazem com que aumentem os investimentos, geralmente oriundos de investidores internacionais, que consequentemente, geram apreciação dos preços;

3. O interesse começa a atingir investidores menos sofisticados, o que dispara um processo de apreciação dos preços dos ativos a uma taxa tal que, neste estágio, o comportamento do mercado torna-se praticamente não correlacionado em relação ao nível de produção de outros ativos reais.

4. Com os preços excessivamente altos, o número de investidores que continuam entrando neste mercado especulativo diminui e o mercado entra em uma fase de nervosismo até um ponto em que, instantaneamente, colapsa.

Este cenário se aplica a essencialmente todos os crashes ocorridos, incluindo os mais antigos como Outubro de 1929 em Wall Street. A robustez desse cenário influencia os investidores de maneira que, em seu comportamento, desenvolve-se uma tendência à imitação e reação frente a más notícias e periodos de instabilidade.

As bolhas financeiras podem ser definidas como um periodo de tempo em que, através de uma prolongada aceleração dos preços, partimos de um ponto mínimo para um ponto máximo seguido por um crash de grandes escalas (bear market).

As bolhas podem ser caracterizadas através da identificação de seu término, onde o mais alto valor do índice é atingido, antecipando o crash, e de seu começo, já 
que coincide com o mais baixo valor atingido pelo indice antes de notarmos mudanças em sua tendência.

\section{1)Castles in the air}

A teoria dos Castles in the air de investimentos (ver Malkiel, 1999), apresentada por John Maynard Keynes em 1936 nos mostra que os investidores profissionais preferem concentrar suas energias nāo em analisar e estimar os valores intrínsecos dos ativos, mas sim, como os outros investidores se comportarão no futuro e como, em tempos de otimismo, concentrarão seus esforços. De acordo com Keynes, a teoria das firmas tem seu valor discutivel. Considerando o mercado financeiro, Keynes afirma que ninguém sabe o que influenciará as projeções de ganhos futuros, fazendo com que os investidores se concentrem, não em fazer previsões de longo prazo de seus investimentos, mas sim em tentar prever mudanças de tendências nos valores dos ativos com um passo à frente do público em geral.

Baseado nesta teoria, os castelos que foram construídos ao longo da história fizeram com que algumas pessoas realizassem lucros excepcionais, no entanto, levaram um maior número delas à total ruína financeira.

\section{O episódio dos bulbos de tulipa}

O episódio dos bulbos de tulipa, na Holanda, é uma das mais fantásticas histórias de bolhas especulativas, ainda mais se levarmos em consideração que aconteceu há mais de três séculos.

Oriundas da Turquia, as tulipas eram bastante populares na Holanda, porém caras. Um virus, chamado Mosaico, atingiu as plantaçōes e começava, então, a grande especulação sobre os bulbos. Tais virus fizeram com que os bulbos se desenvolvessem com aspectos bizarros e, em pouco tempo, quanto mais bizarros eram os bulbos, mais caros eram os custos de se obter um, desencadeando uma tulipomania. 
Os preços dos bulbos de tulipa começaram a subir rapidamente e, quanto mais caros eles ficavam, mais as pessoas viam estes como um ótimo investimento. Contam os historiadores que as pessoas começaram até a vender seus bens pessoais para obter um bulbo de tulipa, imaginando que a paixāo por tais bulbos iria durar para sempre e fazê-las, no futuro, pessoas milionárias. Instrumentos muito parecidos com call options foram desenvolvidos rapidamente. O preço dos bulbos atingiu preços astronômicos. Aparentemente, como acontecem em todas as bolhas especulativas, os preços atingiram um ponto tal que alguém achou prudente vendê-los. Vários outros investidores seguiram a idéia, o que fez com que os preços entrassem em colapso até um ponto em que os bulbos tornaram-se totalmente sem valor, desencadeando um período de grande depressão na Holanda.

\section{O episódio Nasdaq}

Caindo para 3.227 pontos em 17 de abril de 2000, o indice Nasdaq perdeu mais de $37 \%$ em relação ao seu ponto mais alto de 5.133 pontos, atingidos em 10 de Março do mesmo ano.

O índice Nasdaq é composto principalmente por açōes da considerada nova economia, ou seja, os setores de telecomunicações, internet, software e hardware. A grande diferença entre a nova economia e a velha economia (empresas como Procter $\&$ Gamble, Ford, General Electric) é a expectativa quanto aos seus ganhos futuros, ou seja, os investidores esperam um enorme aumento nas vendas de produtos de Internet e computadores. Baseada no princípio básico de avaliação, que define o retorno esperado de uma empresa como sendo a soma de seu fluxo futuro de dividendos, dada uma taxa de crescimento, as empresas da nova economia mostravam-se capazes de compensar seus baixos índices de ganhos presentes por ação(earnings per share) com um fantástico crescimento potencial em relação as da velha economia que apresentavam indices de ganho por ação(earnings per share) muito maiores. Na essência, o mercado comprador que se observou no Nasdaq baseava-se somente em expectativas de ganhos futuros em vez de fundamentos econômicos. 


\section{2) Escopo deste trabalho}

Estes exemplos deixam claro que a expectativa de ganhos futuros é o principal fator que motiva os mercados e não a realidade econômica presente, criando, assim, bolhas especulativas.

De fato, os crashes em bolsas de valores são eventos fascinantes para acadêmicos e praticantes. Baseado na teoria que os mercados são eficientes, a revelação de informações pode, instantaneamente, causar um crash. Para os operadores de mercado, o medo de um crash é sempre uma fonte de incerteza que afeta os niveis de preço.

Nossa hipótese durante todo esse trabalho, referente ao modelo que vamos apresentar, é a seguinte: os crashes são geralmente causados por sucessivos aumentos de correlação que colapsam em um instante crítico. O uso da palavra "crítico" não é somente no sentido literal, ou seja, em termos matemáticos, sistemas dinâmicos complexos atravessam pontos críticos. De fato, quanto mais estudamos sistemas dinâmicos não-lineares, a existência de pontos críticos é mais uma regra do que exceção. É válido e interessante investigar se existe uma conexão entre crashes e pontos críticos (critical points).

No nivel microscópico, o mercado de capitais possui características com forte analogia em relação às áreas da estatística de sistemas complexos. Os traders, individualmente, possuem três estados possiveis: comprar, vender ou esperar. A passagem de um estado para outro é um processo descontínuo devido a algum parâmetro ter sido excedido, geralmente o preço de mercado do ativo. A transição envolve outro trader e o processo é irreversivel, já que o trader não pode vender o ativo de volta para o mesmo trader ao mesmo preço. Em geral, os traders possuem informação das ações de um número parcial de traders e acompanham o efeito global dessas ações individuais no mercado através do aumento ou queda dos preços de mercado. Torna-se natural pensar, então, no mercado de capitais como um sistema complexo com analogias a um sistema dinamicamente fora de equilibrio como, por exemplo, terremotos, avalanches, etc. Uma diferença, no entanto, pode ser apontada: os traders são conscientes de suas açōes. Este fato foi muito bem abordado por Keynes na parábola do concurso de beleza. 
Neste trabalho, apresentaremos um modelo que confrontará a teoria econômica, baseada no postulado das expectativas racionais, e a teoria estatística.

Mostraremos que é possivel construir um modelo dinâmico do mercado de capitais que possa exibir pontos críticos bem definidos que se apresentam de acordo com as expectativas racionais, além de terem um apelo intuitivo. Além disso, as propriedades matemáticas dos pontos críticos são independentes do modelo, muito mais do que os que possuem comportamento regular. Por isso, todas as previsões que o modelo é capaz de fazer devem ser relativamente robustas para modelar falhas de especificação. Devido a isso, exploraremos várias versões do modelo.

Mostraremos também, através de análises estatísticas sobre o mercado acionário, que o comportamento do índice nos mostra que os crashes são pontos outliers.

As previsões que podemos fazer com esse modelo são estatisticamente significativas em vários crashes que ocorreram neste século. É possivel identificar um comportamento crítico nestes mercados muitos anos antes do crash e usar essas informações para prever a data que o sistema se tornará crítico, o que coincide com o dia que o crash poderá se realizar.

A habilidade de prever a data critica é perfeitamente consistente com o comportamento racional dos agentes que assumimos no modelo que estamos apresentando, ou seja, todos eles sabem essa data, o crash mesmo assim ocorrerá e nenhum deles poderá realizar nenhum lucro usando essa informação.

A primeira proposta de conexão entre crashes e pontos críticos foi feita por Sornette (1996) quando identificou tais oscilações caracteristicas no crash da bolsa americana em 1987. Esses resultados foram posteriormente confirmados por Feigenbaum e Freund (1996) nos crashes de 1929 e 1987, apontando que a logfreqüência das oscilações log-periódicas observadas pareciam decrescer conforme o crash se aproximava. Além desses, vários outros grupos já se interessaram pela idéia e aplicaram-na a vários eventos ocorridos no mercado de ações.

Neste trabalho apresentaremos tal modelo e os resultados empiricos obtidos no mercado norte-americano. Além disso, apresentaremos um ensaio ao aplicá-lo aos crashes ocorridos no Brasil na década de 90, principalmente decorrentes da crise asiática, da crise Russa e da desvalorização cambial brasileira de 1999. Apresentaremos também um modelo econômico racional que fundamenta muitos dos 
argumentos usados no modelo. Isso nos leva a algumas implicações fundamentais, ou seja, veremos que a data do crash é aleatória, e por isso, não deve coincidir com a data que o critical point foi calculado para ser.

Apresentaremos, inicialmente, o modelo racional para bolhas e crashes e, em seguida, as propriedades matemáticas comuns a tais fenômenos. Depois disso, discutiremos os resultados empíricos e a conclusão. 


\section{2.) O MODELO}

O modelo de expectativas racionais para crashes pode ser baseado em duas premissas básicas:

1. Em um instante em que a tendência dos traders em imitar as açōes dos vizinhos mais próximos cresce a um ponto que podemos chamar de critical point, todos os traders abandonam um estado de desordem e assumem um estado de ordem de venda em um mesmo momento, causando assim os crashes.

A probabilidade de passagem de um estado para o outro pode ser medida pelo que chamamos de hazard rate (h), ou seja, a probabilidade por unidade de tempo que um crash ocorra, dado que não ocorreu em um instante anterior.

2. Dado que os crashes não são pontos determinísticos, é ainda bastante racional para os traders permanecerem com seus investimentos, já que estão sendo recompensados por maiores taxas de retorno ao assumirem o risco de um crash à medida que $h$ aumenta.

Esse modelo faz uma clara distinção entre o fim de uma bolha e o início de um crash. A data de um crash é aleatória, ou seja, mesmo não sendo muito comum, ela poderia ter iniciado em qualquer instante de tempo anterior ao fim da bolha, ainda que o término da bolha é o instante mais provável de início de um crash. Existe também uma probabilidade finita de que uma bolha acabe sem que um crash ocorra.

Com essas premissas podemos construir um modelo com capacidade para prever esses critical points e perfeitamente consistente com o comportamento dos agentes, ou seja, todos eles conhecem essa data e todos possuem igualdade de condições de ajustar seus lucros a essa informação. 


\section{1)Dinâmica dos preços}

Primeiramente vamos considerar um ativo que não paga dividendos e vamos ignorar as taxas de juros e a aversão ao risco, fazendo com que as expectativas racionais quanto ao retorno desse ativo sejam equivalentes a um processo do tipo Martingale.

$$
\forall t^{\prime}>t \quad E_{t}\left[p\left(t^{\prime}\right)\right]=p(t)
$$

Onde: $p(t)$ denota o preço do ativo no tempo $t$ e $E_{t}[$.] denota a expectativa condicional, dadas todas as informações reveladas até o instante $t$, seguindo a hipótese de mercado eficiente.

Se não permitirmos ao preço do ativo flutuar, dados momentos nervosos no mercado, a solução para a equação (1) é constante: $p(t)=p\left(t_{0}\right)$. Como temos por hipótese que o ativo não paga dividendos, o valor fundamental de $p(t)=0$, e podemos considerar todo valor positivo de $p(t)$ como sendo uma bolha especulativa.

Economicamente, os mercados são considerados eficientes se toda a informação disponivel está refletida nos preços de mercado. Esta aproximação é baseada na teoria das expectativas racionais que surgiu como uma resposta a teoria das expectativas adaptadas. Essa última previa que a expectativa de inflação futura, por exemplo, seria, simplesmente, a média das inflações passadas, o que nos leva a acreditar que mudanças nas expectativas viriam gradativamente com a mudança dos dados observados. Contrário à isso, a teoria das expectativas racionais argumenta que o efeito agregado das previsões individuais para o comportamento futuro de qualquer variável pode ser considerado a melhor previsão usando todos os dados disponiveis.

A teoria de expectativas racionais argumenta que o efeito agregado das expectativas individuais no comportamento de qualquer variável é uma aproximação otimizada de uma previsão feita com todos os dados históricos disponiveis. 
Recentemente, as premissas do modelo de expectativas racionais estão sendo questionadas por vários economistas. Podemos argumentar que, no mercado de ações, os participantes não otimizam suas expectativas, mas sim, seguem tendências.

Para esse modelo, usaremos a premissa que, mesmo que a percepção de um trader seja não otimizada, o efeito agregado nos preços do mercado de ações certamente será.

A condiçāo de não-arbitragem, resultante da teoria das expectativas racionais, descreve uma dinâmica de auto-adaptação dos preços de mercado que provém das inúmeras ações dos traders.

Vamos agora introduzir uma variável exógena de probabilidade de crash (j). Essa variável (j) denota um jump process com valor 0 antes dos crashes e valor 1 no momento após o crash.

A função de distribuição do momento do crash é chamada de $Q(t)$, a função densidade de probabilidade é $q(t)=d Q / d t$ e a hazard rate é $h(t)=q(t) /[1-Q(t)]$. A hazard rate é a probabilidade por unidade de tempo de que um crash ocorra no instante seguinte, dado que não ocorreu no instante anterior. Se assumirmos que, em ocorrendo um crash, os preços cairão por uma taxa percentual fixa $k \in(0,1)$, a dinâmica de preços de um ativo antes de um crash pode ser escrita:

$$
d p=\mu(t) p(t) d t-k p(t) d j
$$

Onde $\mu(t)$ é escolhido de tal forma que o processo de formação de preços satisfaça as condições de Martingale, ou seja, $E_{t}[d p]=\mu(t) p(t) d t-k p(t) h(t) d t=0$. Podemos dizer então que $\mu(t)=k h(t)$. Substituindo na equaçāo (2), obtemos uma equação diferencial ordinária que possui por solução:

$$
\log \left[\frac{p(t)}{p\left(t_{0}\right)}\right]=k \int_{t=o}^{t} h\left(t^{\prime}\right) d t^{\prime} \quad \text { antes do crash. }
$$

Onde $h\left(t^{\prime}\right) d t^{\prime}=h(t) d t-d j$. 
Matematicamente, quanto maior a probabilidade de um crash, mais rapidamente os preços precisam subir para que a condição de Martingale seja satisfeita. Intuitivamente, os investidores precisam ser imediatamente compensados com maiores taxas de retorno por possuírem, em suas posiçōes, ativos com probabilidade alta de crash. Até o momento, este é o único efeito capturado pelo modelo que estamos apresentando. Este efeito vai contra a pré-concepção de que preços são inversamente afetados pela probabilidade de um crash mas o resultado que obtivemos é consistente com o modelo de expectativas racionais. Os preços são diretamente afetados pela hazard rate $h(t)$.

Além disso, a probabilidade de um crash é uma variável exógena, ou seja, nāo é possivel prever exatamente quando ele ocorrerá, o que impede que os traders obtenham grandes lucros ajustados ao risco ao anteciparem qualquer ocorrência de crash. Adicionado a isso, devido ao mesmo motivo, ou seja, crashes são variáveis exógenas, os preços serão perturbados pela chegada de um crash ou pelo aumento de sua probabilidade.

Isso pode parecer insatisfatório, no entanto, é dificil de ver como os crashes podem ser obtidos por modelos de expectativas racionais, ou seja, se os agentes pudessem, de alguma maneira, definir a chegada de um crash, escolheriam que este nunca chegasse, e se pudessem controlar a probabilidade de um crash, eles sempre escolheriam que fosse zero.

Em nosso modelo, os crashes são eventos aleatórios que possuem probabilidades dadas por fatores externos, e uma vez que a probabilidade é dada, esta influenciará diretamente os preços.

\section{2) O Crash}

O objetivo dessa seção é explicar a probabilidade de um crash em termos do comportamento dos agentes, de uma maneira que seja possivel derivar as específicas implicações deste na hazard rate dos crashes $h(t)$.

Um crash acontece quando um grande grupo de agentes começa a dar ordens de venda simultaneamente. Isto cria um desbalanceamento nos livros dos market makers de tal ordem que é impossivel absorver todas elas sem impactar os preços 
para baixo. $O$ interessante é que esses agentes não se conhecem entre si e não combinaram nada anteriormente e não seguiram nenhum líder.

Na maioria das vezes acontece no mercado o que podemos chamar de desordem, ou seja, os agentes discordam entre si mandando simultâneas ordens de compra e venda para o mercado. A questão chave é: Gual o mecanismo que leva os agentes a se organizarem e coordenarem simultâneas ordens de venda?

Todos os traders do mundo estão organizados em rede e influenciam uns aos outros localmente através desta rede, ou seja, se eu estou diretamente conectado com $\mathrm{K}$ agentes, então só existem duas únicas forças que podem influenciar minha opinião: 1) a opinião de $\mathrm{K}$ agentes e 2) o sinal idiossincrático que eu recebo sozinho.

Nossa premissa é que os agentes tendem a imitar a opinião dos outros agentes mais próximos e não contradizê-los. A força 1) cria ordem, enquanto a força 2) cria a desordem de uma maneira que a briga entre a ordem e a desordem é um ponto muito importante para o modelo. No que tange aos preços de mercado, um crash acontece quando a ordem vence a desordem e os períodos de calmaria, por sua vez, acontecem quando a desordem vence.

O interessante é que isto vem exatamente contra o senso comum que caracterizam os períodos de crash como momentos de caos.

Essa premissa nos permite mostrar de que maneira fatos em nivel micro podem determinar os de nivel macro. Além disso, fica mais fácil entender como os crashes podem ocorrer por razões não racionais.

O modelo assume que os crashes são causados simplesmente pela tendência dos agentes em imitarem uns aos outros. Não estamos nos perguntando o porquê dos agentes terem essa tendência, ou seja, isso é tomado como uma premissa básica e resultado de modelos de comportamentos exógenos a este.

\section{3) Modelo Macroscópico}

Baseado na teoria do "mean field", a maneira mais simples de descrever o processo de imitação dos agentes é assumir que a hazard rate $h(t)$ evolui de acordo com a seguinte equação: 


$$
\frac{d h}{d t}=C h^{\delta}, \operatorname{com} \delta>1
$$

Onde C é uma constante positiva.

A teoria do "mean field" aborda a diversidade das açōes de um trader através de uma única efetiva representaçāo de seu comportamento, determinado pela média das interações entre os traders. Por esse raciocinio, $h(t)$ é o resultado coletivo das interações entre os traders, e o termo $h^{\delta}$ modela o fato de que a hazard rate irá crescer ou decrescer dependentemente da presença dessas interaçōes. O expoente $\delta>$ 1 quantifica o número efetivo igual a $\delta$ - 1 interações percebidas por um trader. Matematicamente, a condição de $\delta>1$ é crucial para modelar as interações e é essencial para obter a singularidade (critical point) no tempo finito. Já economicamente, para que essa teoria faça sentido, é necessário assumirmos que um trader típico esteja conectado com mais do que um outro trader, por isso assumi-se que $2<\delta<+\infty$.

Integrando (4), temos:

$$
h(t)=\left(\frac{h_{0}}{t_{c}-t}\right)^{\alpha} \quad, \quad \text { com } \alpha \equiv \frac{1}{\delta-1}
$$

O termo $t_{c}$ é determinado pelas condições originais. O expoente $\alpha$ deve variar entre zero e 1 por razões econômicas, ou seja, se $\alpha$ assumir outro valor qualquer fora do intervalo $(0,1)$, o preço iria para o infinito quando se aproximasse de $t_{c}$, conforme podemos ver pela equação (3).

Assim, é possivel incorporar um ciclo vicioso por onde os preços afetam a probabilidade de um crash. Quanto maiores os preços de mercado, maior a hazard rate ou a taxa de crescimento da probabilidade de um crash. Por esse processo, podemos observar o fenômeno de autoformação de crises, conceito esse que vem ganhando bastante destaque, particularmente com respeito às crises que ocorreram 
na década de 90 no México, Argentina, Tailândia, Korea, Indonésia, Malásia, Hong Kong, Rússia e Brasil.

Todos esses países passaram por recessōes econômicas severas, associadas a um processo de aquisição e perda de confiança (relacionados a problemas de liquidez) por parte dos investidores estrangeiros. Devido ao "jogo de confiança”, esses países se vêem forçados a incrementar suas taxas de juros domésticas, através de políticas macroeconômicas, para convencer investidores estrangeiros a manter suas aplicaçōes, evitando assim, movimentos bruscos nas taxas de câmbio, mas causando momentos de recessão econômica profunda. Tais países ficam condenados a seguir políticas que os deixam cada vez mais vulneráveis a ataques especulativos, ou seja, é possivel que a perda de confiança por parte dos investidores cause uma crise econômica que então justifique a própria perda de confiança, entrando num ciclo vicioso de ataques especulativos provocados.

Se os investidores começam a achar que uma crise econômica pode ocorrer em um determinado pais, eles podem estar absolutamente certos, visto que eles mesmos causarão essa crise. Van Norden e Schaller (1994) propuseram um modelo Markoviano para o comportamento especulativo que possui, como premissa básica, a hipótese de que a supervalorização dos preços de mercado cause aumento na probabilidade de um crash nas bolsas de valores.

Matematicamente, seguindo a aproximação do "mean field", a maneira mais simples de modelar esse efeito é assumirmos que:

$$
\frac{d h}{d t}=D p^{\mu}, \operatorname{com} \mu>0 .
$$

$D$ é uma constante. Esta equação, juntamente com a equação (3), captura o comportamento dos especuladores, ou seja, a falta de confiança, quantificada por $h(t)$, deteriora os preços de mercado, distanciando-os para cima dos seus preços fundamentais. Como conseqüência, os preços devem subir mais ainda para que seja possivel remunerar os investidores pelo maior risco assumido.

Substituindo a equação (6) na equação (3), temos, 


$$
\frac{d^{2} x}{d t^{2}}=k D e^{\mu x}
$$

Onde $x \equiv \ln p$. Essa solução é,

$$
x=\frac{2}{\mu} \ln \left(\frac{\sqrt{\mu k / 2}}{t_{c}-t}\right)
$$

A solução (8) é uma continuação analítica formal da solução geral da equação (14) que será apresentada abaixo para $\beta \rightarrow 0$.

\section{4) Modelo Microscópico}

Podemos considerar uma rede de agentes. Cada um está indexado por um integrante $i=1, \ldots . ., I$ e $N(\hat{i})$ denota um grupo de agentes diretamente conectados ao agente $i$. Por simplificação, podemos assumir que o agente $i$ pode somente assumir um desses dois estados: $S_{i} \in\{-1,+1\}$. Poderíamos interpretar esses estados como sendo de "compra" ou "venda".

Postularemos o estado do trader $i$ determinado por:

$$
s_{i}=\operatorname{sinal}\left(K \sum_{j \in N(i)} s_{j}+\sigma \varepsilon_{i}\right)
$$

Onde a função sinal(.) é igual a +1 para números positivos e -1 para números negativos, $K$ é uma constante positiva e $\varepsilon_{i}$ é independentemente distribuído de acordo com uma distribuição normal.

Neste modelo (9), a tendência a imitar os outros agentes é determinada por $K$, a tendência do comportamento idiossincrático é governado por $\sigma$. Portanto, o valor de 
$K$, relativo a $\sigma$, determina o resultado da batalha entre a ordem e a desordem e, eventualmente, a probabilidade de um crash. Mais genericamente, $K$ pode ser um par heterogêneo, ou até mesmo alguns dos $K_{i j}$ podem ser negativos, quando a média de todos os outros $K_{i j}$ são positivas, que isso não afetaria as propriedades básicas do modelo.

É interessante notar que a equação (9) somente descreve o estado dos agentes em um determinado momento do tempo. No instante seguinte, novos $\varepsilon_{i}$ 's são dados, novas influências são propagadas e os agentes podem mudar este estado. Portanto, o melhor que podemos fazer é determinar uma descrição estatística dos estados. A melhor que descreve a chance de um grande grupo de agentes assumir, em um certo momento do tempo, o estado de ordem é a que podemos chamar de suscetibilidade do sistema, que podemos definir através do termo de influência global(G). Adicionado à equação (9):

$$
s_{i}=\operatorname{sinal}\left(K \sum_{j \in N(i)} s_{j}+\sigma \varepsilon_{i}+G\right)
$$

Guando o termo $G>O$ o estado tenderá a +1 e quando $G<0$, o estado tenderá $a-1$.

Podemos dizer que a equação (9) é um caso especial de (10) quando $G=0$, ou seja, não há influência global.

Se definirmos $M=(1 / I) \sum_{i=1}^{I} s_{i}$ como a média dos estados, podemos provar por simetria que, na ausência de influência global $E[M]=0$, ou seja, os agentes estāo igualmente distribuídos entre os dois estados. Se, por sua vez, houver influência global positiva, os agentes estão mais concentrados no estado positivo, ou seja, $E[M] \times G \geq 0$. Com essa notação, a suscetibilidade do sistema pode ser definida como:

$$
X=\left.\frac{d(E[M])}{d G}\right|_{G=0}
$$


Em palavras, a suscetibilidade mede a sensibilidade da média dos estados a uma pequena influência. A suscetibilidade tem uma segunda interpretação como a variação da média do estado $M$ em torno de sua expectativa (zero) causada por um choque idiossincrático aleatório $\varepsilon_{i}$. Outra interpretação que podemos fazer é que, se considerarmos dois agentes e forçarmos um deles a permanecer em um determinado estado, o impacto que a sua intervenção terá sobre o segundo agente será proporcional a $X$. Por essas razōes, podemos assumir que a suscetibilidade deve corretamente medir a habilidade dos agentes em acordarem em uma única opinião.

Se interpretarmos os dois estados como sendo influenciadores na formação de preços de mercado dos ativos, devemos considerar a sincronia para um único estado como causador de um crash. Portanto, podemos caracterizar o comportamento da hazard rate como seguindo um processo muito similar ao comportamento da suscetibilidade.

Não podemos assumir uma relação de um para um entre hazard rate e suscetibilidade porque há varias outras medidas que podem influenciar o grau de coordenação do sistema como um todo, tais como, comprimento da correlação (distância da propagação da imitação) e outros momentos de flutuação da opinião da maioria. Como mostraremos, todas essas outras quantidades possuem o mesmo comportamento genérico.

\section{5) Redes de interação}

É possivel observar que, no modelo de imitação definido na equação (9), a estrutura da rede afeta a suscetibilidade. Por isso, o modelo propõe duas estruturas alternativas para explicar o comportamento da suscetibilidade.

\subsection{1) Posicionamento bi-dimensional}

A estrutura mais simples é assumirmos que os agentes estão localizados bidimensionalmente no plano Euclidiano. Cada agente possui quatro vizinhos mais 
próximos: norte, sul, leste e oeste. O parâmetro relevante é $K$, que mede a tendência à imitação em relação à tendência ao comportamento idiossincrático. Usando o princípio físico de magnetização dos átomos através de seu movimento, o modelo apresentado se relaciona com o modelo bi-dimensional apresentado por Onsager em 1944 (Ver Johansen e Sornette, 1998). Existe um ponto critico $K_{c}$ que pode determinar as propriedades do sistema. Quando $K<K_{c}$, prevalece a desordem, ou seja a sensibilidade à influência de pequenos grupos é pequena e o processo de imitação só se propaga entre vizinhos muito próximos. Em outras palavras, podemos dizer que a suscetibilidade $X$ do sistema é finita.

Quando $K$ começa a crescer e aproxima-se de $K_{c}$, o estado de ordem começa a surgir e o sistema torna-se sensivel à perturbações, fazendo com que se forme um grande grupo de agentes que concordam entre si, e o processo de imitação se propague a longas distâncias. Em outras palavras, podemos dizer que a suscetibilidade $X$ do sistema tende ao infinito de acordo com a seguinte equação:

$$
X \approx A\left(K_{c}-K\right)^{-\gamma}
$$

Onde $A$ é uma constante positiva e $\Upsilon>0$ pode ser chamado de expoente crítico da suscetibilidade.

Nós não conhecemos a dinâmica do parâmetro chave $K$ do sistema, mas podemos assumir suavidade suficiente para podermos usar expansão de Taylor de $1^{\text {a }}$. ordem em torno do ponto crítico. $K$ não necessariamente precisa ser determinístico, ou seja, $K$ pode ser um processo estocástico, desde que se movimente lentamente.

Assumindo $t_{c}$ de maneira que $K\left(t_{c}\right)=K_{c}$, anteriormente a $t_{c}$, temos a aproximação $K_{c}-K(t) \approx c t e .\left(t_{c}-t\right)$. Usando a aproximação, podemos assumir que a hazard rate dos crashes possui o mesmo comportamento da suscetibilidade do ponto crítico, o que, então, podemos escrever que:

$$
h(t) \approx B\left(t_{c}-t\right)^{-\alpha}
$$


Onde $B$ é uma constante positiva. O expoente $\alpha$ varia entre 0 e 1 por razōes econômicas, ou seja, os preços iriam para infinito quando $t$ se aproximasse de $t_{c}$ sem que a bolha tivesse explodido ainda.

A probabilidade por unidade de tempo de haver um crash no instante seguinte, condicionalmente em não ter havido ainda, torna-se muito alta ao aproximar-se de $t_{c}$.

É importante salientar que $t_{c}$ não é o momento do crash, dado que ela pode ocorrer em qualquer momento anterior a $t_{c}$, embora não seja muito provável. Podemos verificar também que existe uma probabilidade residual $1-Q\left(t_{c}\right)>0$ de atingirmos $t_{c}$ sem que haja o crash. Essa probabilidade residual é crucial para a hipótese de expectativas racionais, já que, caso contrário, os agentes racionais antecipariam o crash.

Este modelo não explica o que acontece no momento $t_{c}$ e nem nos momentos seguintes. Substituindo a equação (13) em (3), obtemos a seguinte dinâmica para a determinação dos preços:

$$
\log [p(t)] \approx \log \left[p_{c}\right]-\frac{k B}{\beta}\left(t_{c}-t\right)^{\beta}
$$

Onde $\beta=(1-\alpha) \in(0,1)$ e $p_{c}$ é o preço em $t_{c}$. Podemos ver que o logaritmo do preço antes do crash segue uma lei de potência. Temos um contorno superior finito $\log \left[p_{c}\right]$. A curvatura do logaritmo do preço, que representa o retorno esperado por unidade de tempo, torna-se incontornável conforme nos aproximamos da data crítica. 


\subsection{2) Hierarchical Diamond Lattice}

O mercado de ações constitui um exemplo de atores que interagem, mas diferem-se entre si quanto à magnitude, indo desde indivíduos até grandes investidores profissionais como fundos de pensão. Adicionando a isso, estruturas de niveis superiores como, por exemplo, a esfera de influência da moeda, globalização e a desregulamentação dos mercados fazem com que a palavra economia comece a fazer parte e comece a interagir nos mercados.

Isso significa que o mercado financeiro possui uma estrutura com níveis hierárquicos onde os traders se espalham por todos os níveis. De fato, podemos observar que organizaçōes horizontais de indivíduos são difíceis de serem encontradas, o que faz com que a rede plana de interação que usamos nas seçōes anteriores é demasiadamente simplificadora.

Podemos então estudar uma nova estrutura de rede para fazer parte da solução do modelo. Vamos começar com um par de traders que estão conectados. Podemos substituir a conexão por uma figura com a forma de um diamante e os dois traders iniciais ocupam, agora, posições em vértices diametralmente opostos. Dois novos traders passam a ocupar outros dois novos vértices, de forma que o diamante agora possui quatro conexōes. Para cada uma dessas conexōes, podemos substituílas por diamantes exatamente com o mesmo procedimento e interagir a operação. $\mathrm{O}$ resultado é um Diamond Lattice.

Após $p$ interações teremos $\frac{2}{3}\left(2+4^{p}\right)$ traders e $4^{p}$ conexōes entre eles. A maioria dos traders possui 2 vizinhos, enquanto que alguns outros possuem $2^{p}$ vizinhos. Os demais estão distribuídos neste intervalo. Podemos notar que o agente que possui o menor número de conexões tem $2^{p-1}$ vezes menos vizinhos do que o mais conectado, que, por sua vez, tem $2^{p}$ menos vizinhos se compararmos com o total de agentes.

Uma versão desse modelo foi desenvolvida por Derrida em 1983. As propriedades básicas são similares as já descritas anteriormente, ou seja, existe um ponto crítico $K_{c}$ onde $K<K_{c}$, a suscetibilidade é finita e tende ao infinito quando 
$K$ se aproxima de $K_{c}$. A principal diferença é que o expoente pode ser um número complexo. A solução geral para a suscetibilidade é a soma dos termos, assim como na equação (12) só que com expoentes complexos.

A expansão de primeira ordem da solução geral fica:

$$
\begin{aligned}
X & \approx \operatorname{Re}\left[\mathrm{A}_{0}\left(K_{c}-K\right)^{-\gamma}+\mathrm{A}_{1}\left(K_{c}-K\right)^{-\gamma+i \omega}+\ldots\right\rfloor \\
& \approx \mathrm{A}_{0}^{\prime}\left(K_{c}-K\right)^{\gamma}+\mathrm{A}_{1}^{\prime}\left(K_{c}-K\right)^{\gamma} \cos \left[\omega \log \left(K_{c}-K\right)+\psi\right]+\ldots
\end{aligned}
$$

Onde $A_{0}^{\prime}, A_{1}^{\prime}, \omega$ e $\psi$ são números reais e Re[.] denota a parte real de um número complexo. Podemos verificar que, agora, a lei de potência está corrigida por oscilações em que a freqüência explode conforme nós nos aproximamos do ponto crítico. Essas oscilaçōes são chamadas de log-periódicas, e $\omega / 2 \pi$ pode ser chamado de log-freqüência.

Seguindo os mesmos passos da seção anterior, podemos então definir a hazard rate de um crash como:

$$
h(t) \approx B_{0}\left(t_{c}-t\right)^{-\alpha}+B_{1}\left(t_{c}-t\right)^{-\alpha} \cos \left[\omega \log \left(t_{c}-t\right)+\psi^{\prime}\right]
$$

Mais uma vez, a hazard rate de um crash explode próximo da data crítica, com a exceção de que, agora, apresenta oscilações log-periódicas. A evolução dos preços antes do crash é dada por:

$$
\log [p(t)] \approx \log \left[p_{c}\right]-\frac{k}{\beta}\left\{B_{0}\left(t_{c}-t\right)^{\beta}+B_{1}\left(t_{c}-t\right)^{\beta} \cos \left[\omega \log \left(t_{c}-t\right)+\phi\right]\right\}
$$

Onde $\phi$ é uma constante. As oscilações aparecem nos preços dos ativos antes da data crítica. O máximo local da função é separado por intervalos de tempo que tendem a zero na data crítica. A razão dos intervalos de tempo consecutivos é uma constante: 


$$
\lambda \equiv e^{\frac{2 \pi}{\omega}}
$$

Esta definição é muito útil do ponto de vista empírico, uma vez que tais oscilações são mais visíveis agora do que na lei de potência. Um ajuste no modelo pode travar as oscilaçōes que contem informaçōes sobre a data crítica $t_{c}$. Se tais oscilações estão presentes, elas podem ser usadas para prever $t_{c}$ simplesmente extrapolando a aceleração de freqüência.

Já que a probabilidade de um crash é maior perto de $t_{c}$, podemos usar esse procedimento como um interessante exercício de previsibilidade. É interessante notarmos que, para traders racionais em nosso modelo, todo exercício de previsão é inútil, já que todos eles já conhecem a hazard rate $h(t)$ em todos os pontos, incluindo $t_{c}$, e essas informações já estão refletidas nos preços conforme podemos observar na equação (3).

\section{6) Generalização}

Apesar das previsibilidades das seçōes anteriores serem bem detalhadas, tentaremos argumentar que elas são apenas relativamente robustas para modelar falhas de especificaçāo.

Os modelos de crash que combinam as seguintes premissas:

1. Um sistema de traders que sāo influenciados por seus vizinhos;

2. Imitação propagando-se espontaneamente;

3. Cooperação global entre os traders causando crash;

4. Preços relacionados às propriedades do sistema;

5. Parâmetros dos sistemas evoluindo através do tempo; 
apresentariam as mesmas características que o que estamos estudando, ou seja, onde os preços seguem uma lei de potência por volta do critical date, seja com um expoente real ou complexo. Todos esses modelos devem ter em comum que o crash terá sua maior probabilidade de ocorrência quando o sistema de imitação atingir um ponto crítico (critical point).

Um sistema atinge seu ponto crítico quando a influência local se propaga para longas distâncias e o estado do sistema torna-se sensivel a pequenas perturbações, ou seja, as partes do sistema tornam-se altamente correlacionadas. Outra característica deve ser que os sistemas críticos são similares através das escalas, ou seja, aplicado ao modelo, um grande grupo de traders, que esteja na posição comprada (Bullish), possui, internamente, diversos outros grupos menores que estão na posiçāo vendida (Bearish), que por sua vez, também possuem, internamente, outros grupos bullish. Essa progressão continua até seu menor ponto que é o próprio trader.

Devido a isso, ou seja, que os sistemas sāo invariantes através das escalas, seu comportamento perto do ponto crítico necessita ser representado por uma lei de potência, seja com expoentes reais ou complexos, já que é a única familia de funçōes que apresenta características homogêneas, ou seja, mantém-se inalteradas quando seus argumentos são rescalados por uma constante (multiplicação escalar), Matematicamente, a invariância da escala está associada à seguinte equação:

$$
F(\not x)=\delta F(x)
$$

Onde $F$ é uma função suscetibilidade, $x$ é um parâmetro e $\delta$ é uma constante positiva que descreve como as propriedades do sistema se alteram quando o sistema é rescalado pelo fator $\gamma$. A solução geral para a equação (20) é:

$$
F(x)=x^{\log (\delta) / \log (\gamma)} \pi\left[\frac{\log (x)}{\log (\gamma)}\right]
$$


Onde $\pi$ é uma função periódica de período 1. A equação (16) pode ser definida de tal maneira que possamos obter uma aproximação de ordem entre 0 e 1 na expansão de Fourier da função $\pi$.

Em geral, físicos estudam pontos críticos através de equações como a (20) para descrever o comportamento do sistema ao longo de diferentes escalas e analisando as propriedades matemáticas dessas equações. Isso ficou conhecido como renormalization group theory (renormalization refere-se ao processo de rescala e group refere-se ao fato que ao iterarmos a equação (21) geramos uma equação similar com fator escalar $\gamma$ ).(Wilson 1979, ver Johansen e Sornette, 1998).

Antes que o renormalization group fosse estudado, para que o comportamento de um sistema critico fosse corretamente descrito em todas as escalas simultaneamente, usava-se métodos de aproximação padrão, já que se obtinha resultados satisfatórios. O renormalization group, contudo, construiu uma solução precisa no que tange a similaridade do sistema através das escalas.

Para o modelo, porém, o importante é a idéia de que a ocorrência massiva do movimento de venda nos mercados durante um crash se dá devido ao processo de imitação, que se espalha através de escalas dentro da cooperação global, quando um sistema complexo se aproxima de seu ponto crítico. As implicações desse movimento foram descritas nas equaçōes (14) e (18).

Essas equações são aproximaçōes válidas somente ao redor do ponto crítico. Sornette e Johansen (1997) propuseram uma fórmula geral com maior grau de liberdade, que nos permite melhor capturar o comportamento longe do ponto crítico. Esses graus de liberdade foram introduzidos através de uma melhor análise da renormalization group theory. O que equivale a incluir um termo de ordem superior na expansão ao redor do ponto crítico:

$$
\log \left[\frac{p_{c}}{p(t)}\right] \approx \frac{\left(t_{c}-t\right)^{\beta}}{\sqrt{1+\left(\frac{t_{c}-t}{\Delta_{t}}\right)^{2 \beta}}}\left\{B_{0}+B_{1} \cos \left[\omega \log \left(t_{c}-t\right)+\frac{\Delta_{\omega}}{2 \beta} \log \left(1+\left(\frac{t_{c}-t}{\Delta_{t}}\right)^{2 \beta}\right)+\phi\right]\right\}
$$

Onde introduzimos os parâmetros $\Delta_{t}$ e $\Delta_{\omega}$. Dois novos efeitos são incluídos nesta equação: 1) Longe do ponto critico a lei de potência perde velocidade e 2) a log- 
freqüência vai de $\frac{\omega+\Delta \omega}{2 \pi}$ para $\frac{\omega}{2 \pi}$ conforme nos aproximamos do ponto crítico. As duas transições acontecem no mesmo intervalo de tempo $\Delta_{t}$. Além disso, complementando o que nos mostra a equação (18), permitimos que os preços oscilem em um nivel constante com uma log-periodicidade diferente. Essa generalização descreve o preço por um período maior antes do crash do que a fórmula original, no entanto ainda captura exatamente o mesmo fenômeno. Podemos notar ainda que, para um $\frac{t_{c}-t}{\Delta_{t}}$ pequeno, a equaçāo (22) aproxima-se da equação (18).

Gostaria de ressaltar que, ao substituirmos a equação (18) pela equação (22), não implica somente em aumentar o número de variáveis na função que descreve a evoluçāo dos preços dos mercados ao longo do tempo. Estamos incluindo um termo de ordem superior na expansão da solução (21) para a equação (20) 


\section{3.) RESULTADOS EMPIRICOS JÁ OBSERVADOS}

\section{1) Os crashes são pontos outliers}

Como foi exposto nas seçōes anteriores, os crashes ocorridos no mercado são precedidos de bolhas especulativas apresentando, como característica principal, os preços de mercado acelerando segundo a lei de potência com oscilaçōes logperiódicas (as oscilações são periódicas no logaritmo do momento do crash). Podemos assim demonstrar que a equação (22) quantifica a evolução do tempo de uma bolha em termos do preço, terminando em um crash ou com grandes correções perto de $t_{c}$.

A distribuição dos retornos do mercado de ações possui o que chamamos de "fat tails", ou seja, uma queda em um dia de 5\% no índice Down Jones ocorre normalmente a cada dois anos, enquanto que um estudo baseado na distribuição Gaussiana preveria que esse mesmo evento deveria ocorrer a cada 1.000 anos. Além disso, a volatilidade nos mercados emergentes é muito maior do que em mercados de ações mais desenvolvidos.

Essas observações empíricas levaram ao desenvolvimento de modelos mais sofisticados do que o Gaussiano, envolvendo volatilidades não-estacionárias como modelos GARCH, que melhor reproduzem a estatística da flutuação do mercado de ações. Crashes, por sua vez, são pontos mais extremos que não podem ser contabilizados como extrapolações da distribuição de eventos de menor magnitude, pois pertencem a outro regime, outra distribuição, ou seja, são outliers.

Para que seja possivel testar esse fato empiricamente, primeiramente é preciso ajustar uma distribuição para os chamados "draw downs". Draw down (DD) pode ser definido como uma queda diária persistente no indice das bolsas por dias consecutivos. No indice Down Jones, por exemplo, é considerado um draw down, quedas diárias, ao comparar os preços de fechamento, maiores que $1 \%$. Podemos estabelecer que a distribuição que melhor ajusta os dados do Down Jones de 1900 até 1994, é a distribuição exponencial com uma constante de queda $D D_{c}$ de $1,8 \%$ e $N_{0}=2789$. 


$$
N(D D)=N_{0} e^{-|D D| / D D_{c}}
$$

Um ponto importante, destacado pelos estudos de Johansen e Sornette (1999), é a constatação da presença de três eventos que não deveriam ter ocorrido, dados os parâmetros da distribuição que foram usados, ou seja, dada a equação (23), quedas iguais ou maiores que $23,6 \%$ só deveriam ocorrer 0,0056 vez por século, e no entanto, constatamos a presença de 3 eventos. Esses eventos podem ser atribuídos à Crise de 1929, à primeira grande guerra e ao Crash de 1987, o que nos faz concluir, empiricamente, que grandes draw downs ou crashes são resultantes de mecanismos diferentes, como os discutidos ao longo desse trabalho.

A distribuição exponencial contempla somente draw downs de amplitudes até $15 \%$, ou seja, todos os draw downs menores do que $15 \%$ são bem ajustados pela distribuição exponencial com uma constante de queda de 1,8\%. Essa constante de queda significa que a probabilidade de haver quedas diárias maiores do que $1,8 \%$ é $37 \%$. Para quantificarmos o quanto esses três eventos desviam da equação (23), é possivel calcular, de acordo com a distribuição exponencial, qual seria o intervalo de tempo típico de ocorrência de um draw down de amplitude igual ao ocorrido no crash de 1987, que foi de $23.6 \%$. Esse número seria o número de séculos $n$ tal que $0.0056 . n \sim 1$, o que nos leva a 180 séculos, quando que, na realidade, os 3 ocorreram em menos de 1 século.

Ao estudarmos a distribuição exponencial dos draw downs maiores de $1 \%$, podemos ver que ela sugere que o comportamento considerado normal do índice do mercado de ações é governado por um processo aleatório, ao passo que, grandes crashes derivam do comportamento e correlações entre os traders.

Ainda para confirmar a hipótese de que esses pontos são considerados pontos outliers, é possível aplicar uma ferramenta mais sofisticada do que a distribuição exponencial dos draw downs, ou seja, um modelo $\operatorname{GARCH}(1,1)$ ajustado através da média do Down Jones.

Uma vez que o índice do mercado de açōes não pode assumir valores negativos, trabalha-se com o logaritmo do índice, e assim, preserva-se a hipótese de que as variações normais diárias no retorno das ações seguem um random walk. No entanto, o logaritmo dos retornos não possui uma distribuição normal e sim uma 
distribuição com caldas mais gordas como a T-student. Além disso, a variância em torno da média deveria ocorrer em função do tempo de maneira correlata.

É possivel gerar, por simulação, 10.000 conjuntos de dados independentes que correspondem a 1 milhão de anos de negociação com indice de ações e que se zeram a cada século. Nesses 10.000 conjuntos de dados só foi possivel observar 3 draw downs maiores do que $22 \%$ em 2 deles e nenhum apresentou mais do que 3 . Interessante também ressaltar que os crashes observados nesses 10.000 conjuntos de dados eram precedidos de draw ups de tamanhos compativeis com os draw downs , o que significa que em 1 milhão de negócios gerados, nenhuma vez ocorreu 3 crashes assimétricos em um mesmo século.

Com essa análise, podemos assumir que os três grandes crashes que ocorreram neste século tiveram uma origem diferente de pequenos draw downs. Podemos sugerir que esses três eventos podem ser vistos como critical points e então podemos quantificar suas principais características.

\section{2) Ajuste do modelo para o mercado de ações}

Ajustar o modelo para o mercado de ações com uma fórmula complexa, como a equação (18) e a equação (22), envolve uma série de considerações, onde a principal delas é assegurar que estamos obtendo o melhor ajuste possível. Ajustar uma função para uma série de dados não é nada mais do que o algoritmo minimizado de uma função-custo dos dados e a função-ajuste. No entanto, com dados perturbados e uma função-ajuste com muitos graus de liberdade, muitos mínimos locais da função-custo podem ser atingidos, não permitindo que o algoritmo minimizado possa atingir seu minimo global.

Para reduzirmos o número de parâmetros livres no ajuste, podemos rescrever as equações (18) e (22), de uma maneira tal, que a função-custo tenha derivada zero em relaçāo a $\mathrm{A}, \mathrm{B}, \mathrm{C}$, ou seja, rescrevendo-as como $\log (p(t)) \approx A+B f(t)+C g(t)$, entāo temos 3 equaçōes lineares em A,B,C: 


$$
\sum_{i=1}^{N}\left(\begin{array}{c}
\log \left(p\left(t_{i}\right)\right) \\
\log \left(p\left(t_{i}\right)\right) f\left(t_{i}\right) \\
\log \left(p\left(t_{i}\right)\right) g\left(t_{i}\right)
\end{array}\right)=\sum_{i=1}^{N}\left(\begin{array}{ccc}
N & f\left(t_{i}\right) & g\left(t_{i}\right) \\
f\left(t_{i}\right) & f\left(t_{i}\right)^{2} & f\left(t_{i}\right) g\left(t_{i}\right) \\
g\left(t_{i}\right) & f\left(t_{i}\right) g\left(t_{i}\right) & g\left(t_{i}\right)^{2}
\end{array}\right)\left(\begin{array}{l}
A \\
B \\
C
\end{array}\right)
$$

resolvendo, dada cada escolha de valores, para cada um dos parâmetros nãolineares, então, as equações (24) podem ser resolvidas expressando A,B e C como funções das funções não-lineares. Disso ainda podemos completar que $\phi$ é apenas uma unidade de tempo. Se mudarmos a unidade de tempo dos dados, podemos demonstrar que $\beta$ e $\omega$, assim como o momento do crash representado por $t_{c}$, são independentes de $\phi$. Isto posto, podemos concluir que ficam, então, três parâmetros controlando o ajuste da equação (18) e cinco controlando a equação (22), que, para o modelo, pode ser considerado um número alto. Devido a isso, para proceder com o ajuste, é necessário ajustar $\beta$ e $\phi$ com valores fixos para os demais parâmetros. Para todos os outros ensaios, que convergem com $0<\beta<1$, eles devem ser reajustados com todos os parâmetros não lineares livres. O racional para tal restrição é exatamente a exposta na seção 2.5 , ou seja, $\beta<0$ implicaria que o índice de ações poderia ir para o infinito.

No caso da equação (18), esse procedimento produzirá um ou mais mínimos distintos. Infelizmente, no caso da equação (22), vários conjuntos de parâmetros diferentes podem produzir o mesmo valor de variância. Essa degeneração da variância em função de $\alpha, t_{c}, \omega, \Delta_{t} e \Delta_{w}$ significa que o erro do ajuste não é o suficiente para decidir se o ajuste é bom ou não. Naturalmente, variância grande significa que o ajuste é ruim, mas o inverso nāo é necessariamente verdade.

Se retomarmos para a derivação das equaçōes (18) e (22), devemos destacar três observaçōes: 1) $\alpha$ determina a amplitude da singularidade. 2) A freqüência $\omega \approx 2 \pi / \ln \lambda$ é determinada pela estrutura hierárquica quantificada pelo fator de rescalonamento $\gamma^{n}$, como definimos anteriormente. 3) $\Delta_{t}$, na equação (22), descreve a transição entre os dois regimes da dinâmica. Essas considerações trazem conseqüências: se acreditarmos que grandes crashes podem ser descritos como 
critical points, então $\beta, \omega$, (na verdade $\gamma$ ) e $\Delta_{t}$ devem ter valores comparáveis, e ainda, $\Delta_{t}$ deveria ser muito menor ou muito maior do que o intervalo de tempo do ajuste, já que descreve o tempo de transição. Isto posto, podemos usar os valores de $\beta, \omega$, juntamente com o erro do ajuste, para descriminar entre ajustes bons e ruins.

\section{3) Estimação da equação (18)}

Como nos mostra os estudos de Sornette (1998) e Feigenbaum e Freund (1996) (ver Johansen e Sornette, 1998), para o periodo anterior ao crash de 1987, o melhor ajuste da equação (18) apresenta oscilações log-periódicas bastante fortes.

A posição de $t_{c}$ foi dada próxima da data do crash, ou seja, os resultados obtidos foram :

$$
A \approx 412, B \approx-165, t_{c} \approx 87,74, C \approx 12, \omega \approx 7,4, \phi \approx 2,0, \beta \approx 0,33
$$

Esses mesmos autores ainda ajustaram dados para o crash de 1929.

Assim como foi feito para o crash de 1987, tal procedimento também foi aplicado ao indice Hang Seng, ajustando a equação (18) com dados 2,5 anos anteriores ao crash de outubro de 1997. Os valores obtidos foram:

$$
A \approx 2.10^{4}, B \approx-8240, t_{c} \approx 97,74, C \approx-397, \omega \approx 7,5, \phi \approx 1,0, \beta \approx 0,34
$$

É possivel notar o comportamento similar dos 2 indices quando nos aproximamos de $t_{c}$, ou seja, $\omega$ e $\beta$ apresentaram resultados muito próximos.

\section{4) Estimação da equação (22)}

Para capturar a evolução dos preços das açōes por um maior período anterior ao crash, podemos estimar a equação (22). 
Para isso, devemos conservar o mesmo método já usado. De novo, devemos formar uma função objetivo dependendo somente de $t_{c}, \beta, \omega e \phi$ e também das duas variáveis $\Delta_{t} e \Delta_{\omega}$. Não se pode colocar nenhuma fronteira para a segunda freqüência $\Delta_{\omega}$, mas desde que $\Delta_{t}$ é o tempo de transição entre os dois regimes, ele deve obedecer a restrição $3<\tau<16$ anos. Assim como para a equação (18), a nãolinearidade da função objetivo criará vários pontos de mínimos locais.

Pode-se observar que o comportamento do logaritmo dos índices são bem capturados pela equação (22) quase 8 anos antes das datas do crash, com erro abaixo de $10 \%$ para os dois casos. Além disso, os valores de $t_{c}$ ficaram apenas 2 semanas distantes da data real. Os resultados são:

Para o S\&P500:

$$
A \approx 5.9, B \approx-0,38, t_{c} \approx 87,81, C \approx 0,043, \omega \approx 8,9, \beta \approx 0,68, \Delta_{t}=11 \text { anos, } \Delta_{\omega}=18
$$

Para o Down Jones:

$$
A \approx 61, B \approx-0,56, t_{c} \approx 29,84, C \approx 0,08, \omega \approx 5,0, \beta \approx 0,63, \Delta_{t}=14 \text { anos, } \Delta_{\omega}=-70
$$

A razão pela qual devemos ajustar o logaritmo dos indices e não o índice propriamente dito é para retirar a tendência exponencial que existe nas séries. 


\section{4.) APLICACÃO AO MERCADO BRASILEIRO}

\section{1)Identificação de pontos outliers}

Os resultados obtidos da aplicação do modelo ao mercado acionário norteamericano certamente despertam a atenção e curiosidade de vários estudiosos e praticantes do mercado.

Movida por tal curiosidade, desenvolvi uma tentativa de aplicação aos crashes ocorridos no Brasil na década de 90, com o objetivo de analisar se tais pontos possuem o mesmo comportamento dos encontrados nos estudos anteriores, e assim, analisar se é possivel estimá-los e prevê-los ao longo do tempo.

Para isso, selecionei os dados diários do IBOVESPA dolarizado desde 1986, como podemos ver no gráfico abaixo:

Gráfico 4.1.1 - IBOVESPA DOLARIZADO

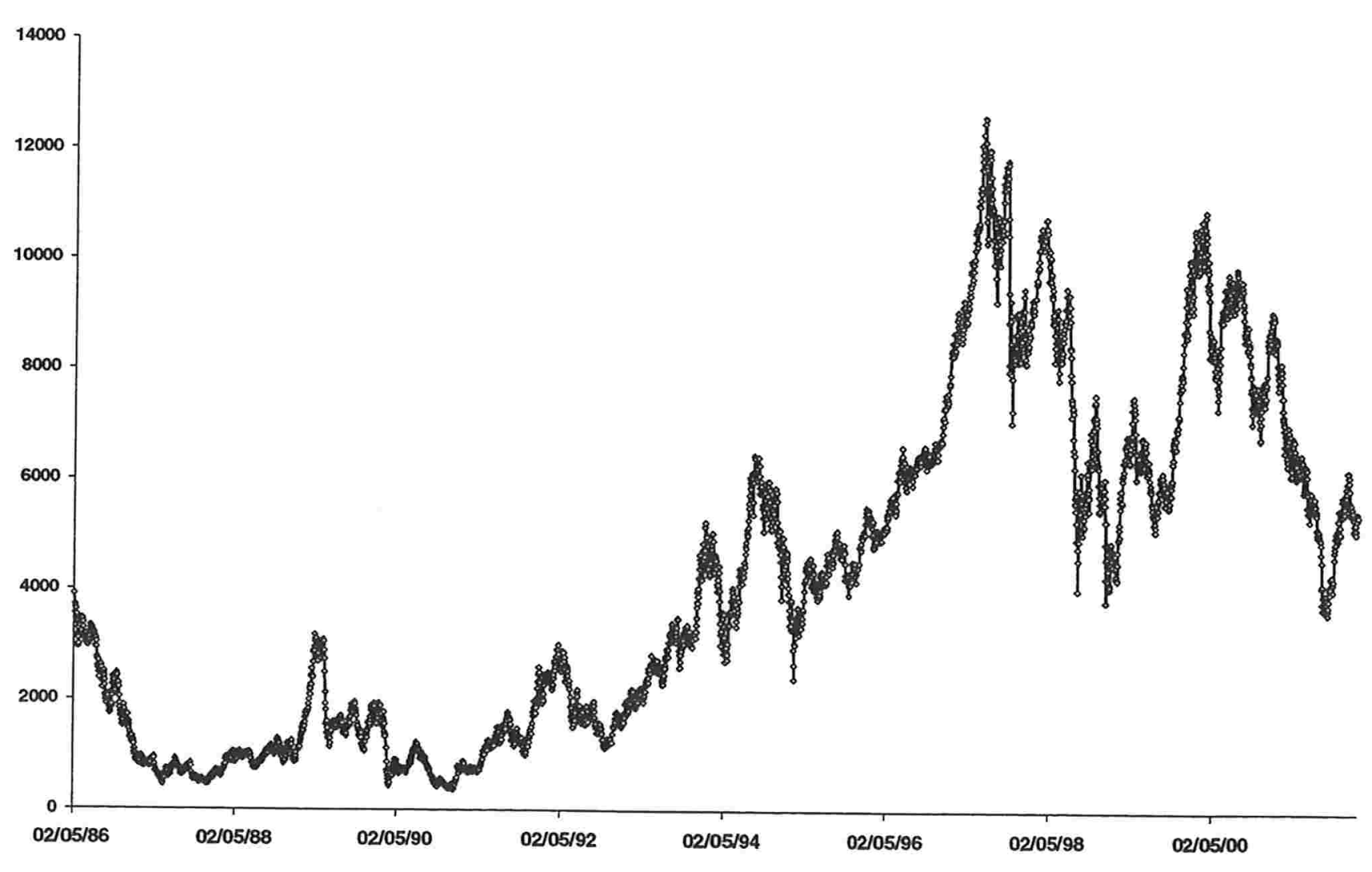


Aplicando o conceito já exposto que crashes são pontos mais extremos que não podem ser contabilizados como extrapolações da distribuição de eventos de menor magnitude pois pertencem a outro regime, ou seja, sāo outliers, podemos ajustar uma distribuição exponencial às quedas do IBOVESPA e constatarmos suas presenças.

Para isso vamos considerar também as quedas diárias maiores que $1 \%$. O histograma que obtemos, com intervalos de confiança com $2,4 \%$ de tamanho, é: Gráfico 4.1.2 - HISTOGRAMA - QUEDAS MAIORES QUE 1\% DO IBOVESPA

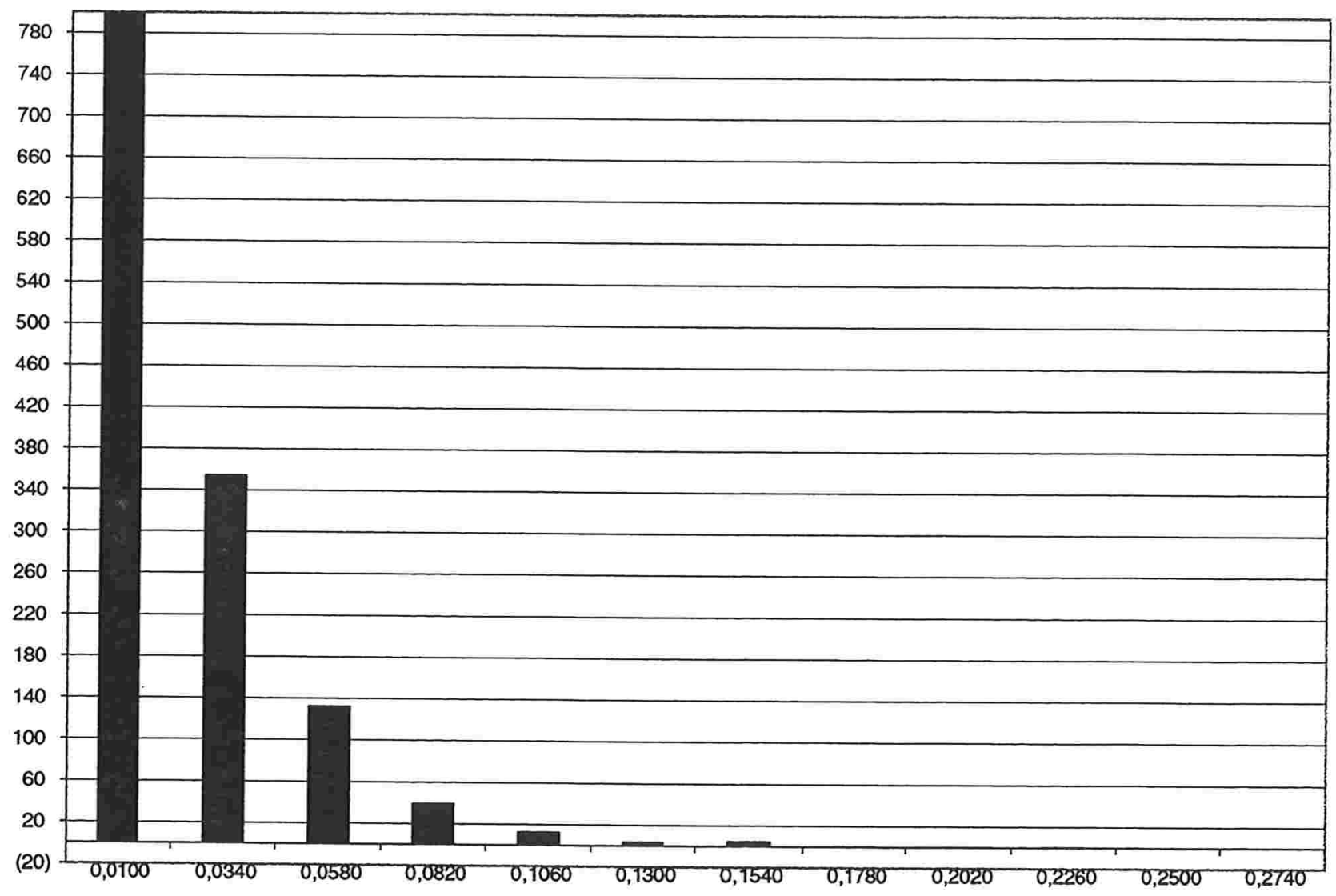

Podemos então ajustar uma distribuiçāo exponencial com constante de queda $D D_{c}$ de $1,2095 \%$ e $N_{0}=1351$, como nos mostra o gráfico abaixo: 
Gráfico 4.1.3 - AJUSTE DISTRIBUIÇĀO EXPONENCIAL

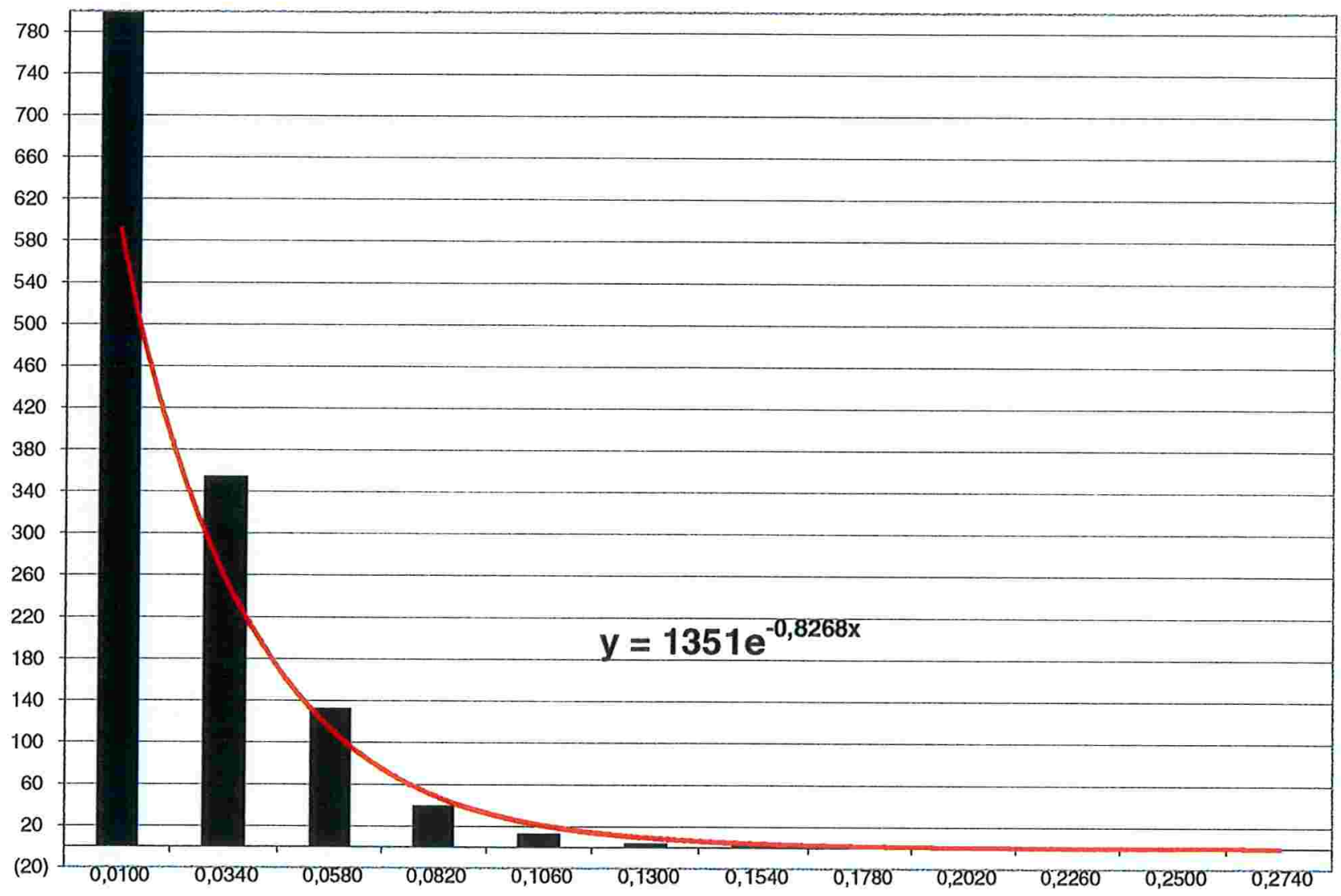

Ao aplicarmos na equação (23), podemos observar que, dada a distribuição que ajustamos, quedas maiores do que 12,5\% para o período de Janeiro de 1986 à Fevereiro de 2002 são esperadas não mais do que 0,0439, no entanto podemos observar a ocorrência de 12 eventos, ou seja, outliers à distribuição que foi possível ajustar aos dados selecionados. 
Tabela 4.1.1 - PONTOS OUTLIERS E CRASHES OCORRIDOS

\begin{tabular}{|c|c|c|}
\hline DATA & GUEDA & FATO ASSOCIADO \\
\hline $13 / 01 / 1999$ & $12,80 \%$ & Desvalorização cambial \\
\hline $03 / 07 / 1989$ & $13,11 \%$ & Escândalo Naji Nahas \\
\hline $16 / 06 / 1989$ & $14,29 \%$ & Escândalo Naji Nahas \\
\hline $13 / 06 / 1989$ & $14,65 \%$ & Escândalo Naji Nahas \\
\hline $27 / 10 / 1997$ & $15,09 \%$ & Crise asiática \\
\hline $29 / 06 / 1992$ & $15,57 \%$ & Impeachement Collor \\
\hline $19 / 03 / 1990$ & $15,72 \%$ & Anúncio Plano Collor \\
\hline $10 / 09 / 1998$ & $15,84 \%$ & Crise russa \\
\hline $21 / 03 / 1990$ & $16,14 \%$ & Anúncio Plano Collor \\
\hline $20 / 10 / 1987$ & $16,54 \%$ & Moratória brasileira \\
\hline $18 / 01 / 1989$ & $18,05 \%$ & Escândalo Naji Nahas \\
\hline $20 / 03 / 1990$ & $22,88 \%$ & Anúncio Plano Collor \\
\hline
\end{tabular}

Dentre esses pontos, podemos destacar os ocorridos em 27/10/1997, 10/09/1998 e 13/10/1999, ou seja, pontos que representam os efeitos da crise asiática, crise russa e desvalorização da moeda nacional, no mercado acionário brasileiro.

\section{2) Estimação dos parâmetros usando a equação (18)}

O objetivo no momento é estimar os parâmetros para os crashes ocorridos em 1997,1998 e 1999, respectivamente associados a crise asiática, crise russa e desvalorização cambial brasileira, e analisar o ajuste, destacando principalmente o ajuste para $t_{c}$ e $\omega$, que representam a data do final das bolhas e início do crash e o movimento log-periódico forte que existe para períodos anteriores ao crash. 


\subsection{1) Crise asiática}

Para estimar os parâmetros para a crise asiática, selecionei os dados de janeiro de 1996 até outubro de 1997, período que envolve a formação da bolha e início do crash, conforme mostra o gráfico abaixo:

Gráfico 4.2.1.1: CRISE ASIÁTICA

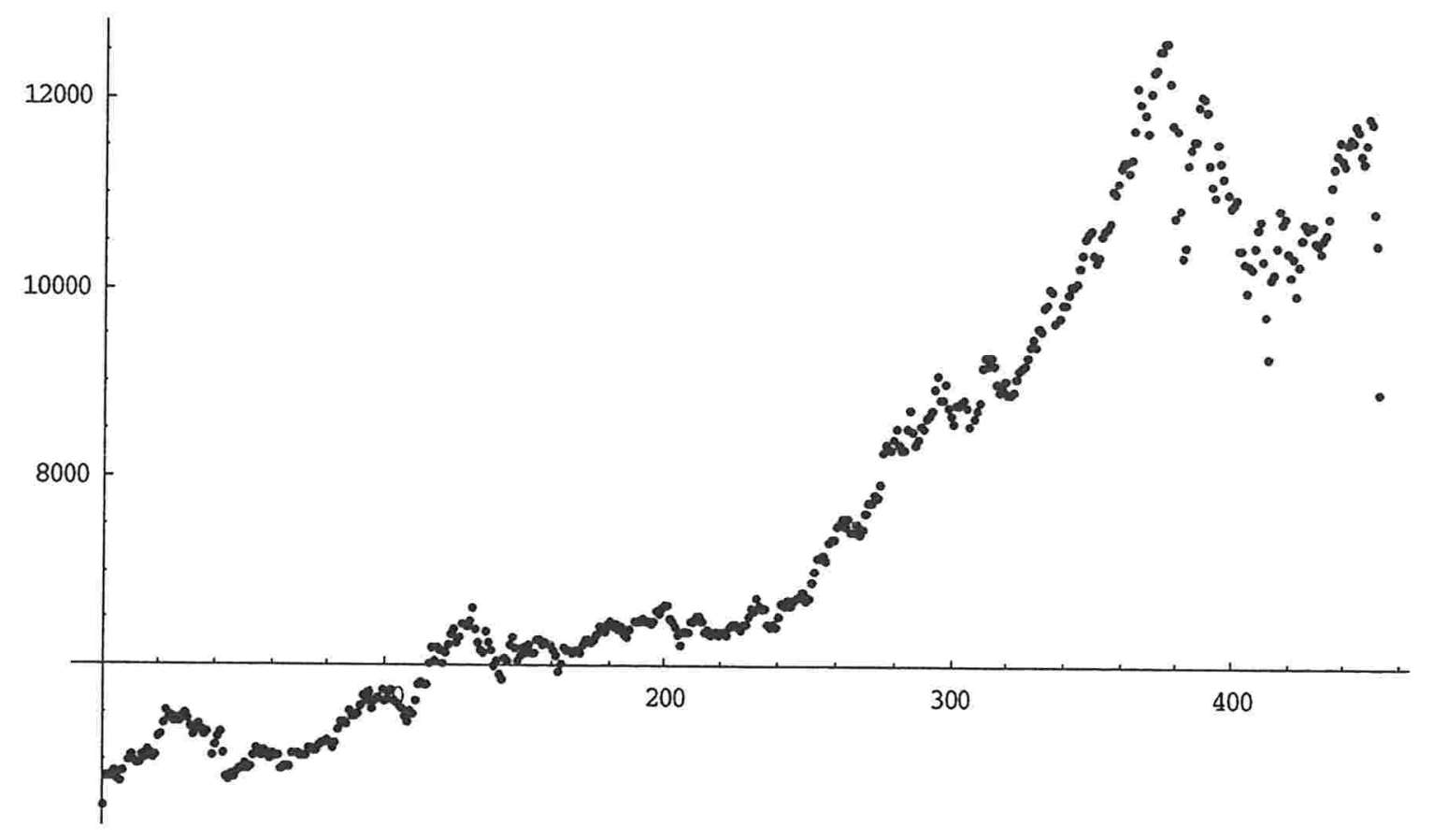

Usando o software "Mathematica", e o método de minimos quadrados, o melhor ajuste conseguido foi:

$$
A \approx 6,969, B \approx 3,048, t_{c} \approx 452,291, C \approx-0,074, \omega \approx 4,164, \beta \approx 0,08
$$

O dado número 452 da série selecionada refere-se ao dia 26/10/1997, data estimada pelo modelo para início do crash, que podemos confrontar com a data observada 27/10/1997. Podemos notar também que o comportamento de $\omega$ ficou alto, como poderiamos esperar. O ajuste que encontramos é como mostra o gráfico abaixo: 
Gráfico 4.2.1.2: AJUSTE DO MODELO x LOG PREÇO IBOVESPA PARA O PERIODO - CRISE ASIÁTICA

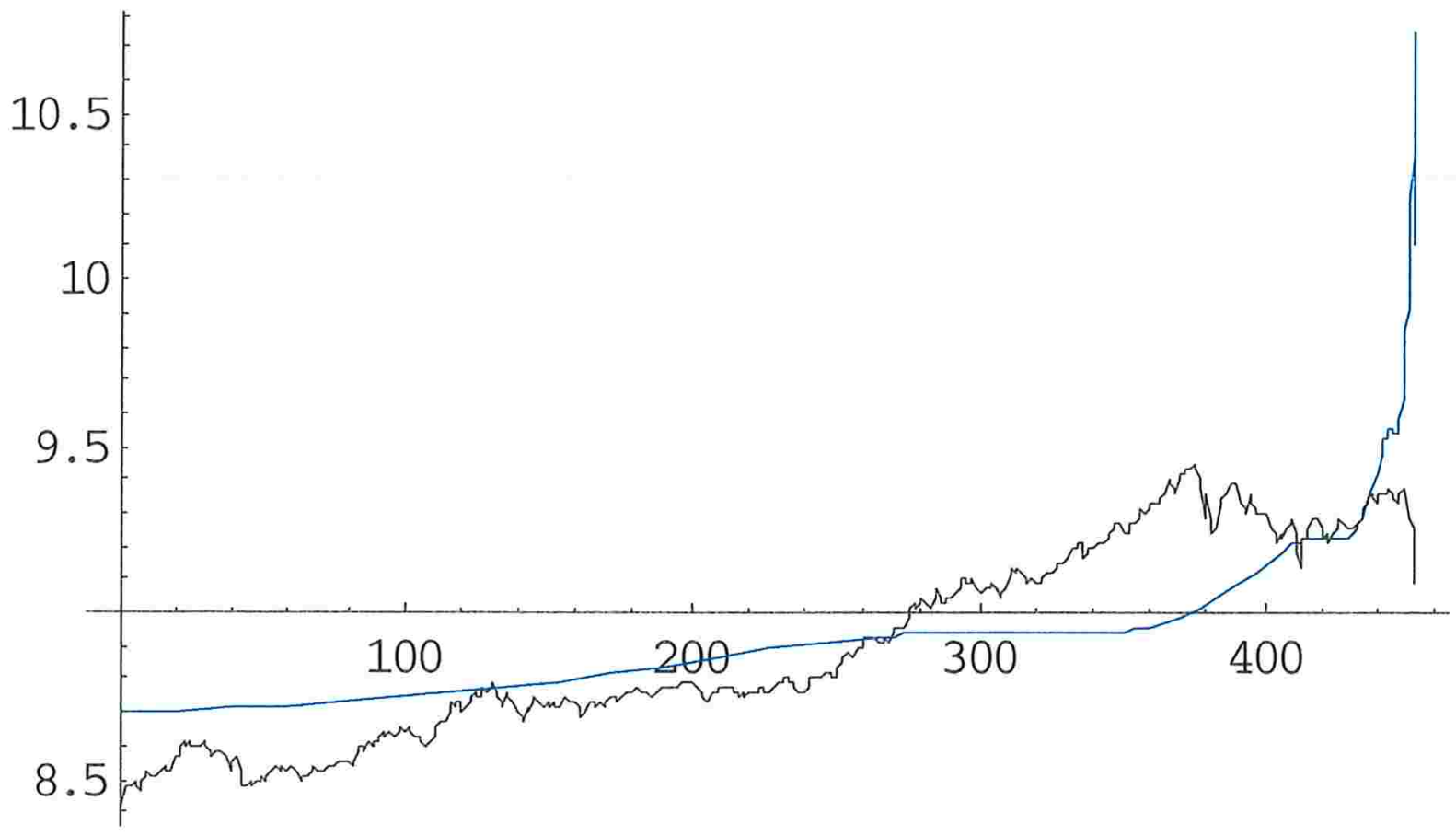

\subsection{2) Crise russa}

Já para estimar os parâmetros para a crise russa, foi necessário selecionar os dados de outubro de 1997 até setembro de 1998, periodo que envolve a formação da bolha e início do crash, conforme mostra o gráfico abaixo:

Gráfico 4.2.2.1: CRISE RUSSA

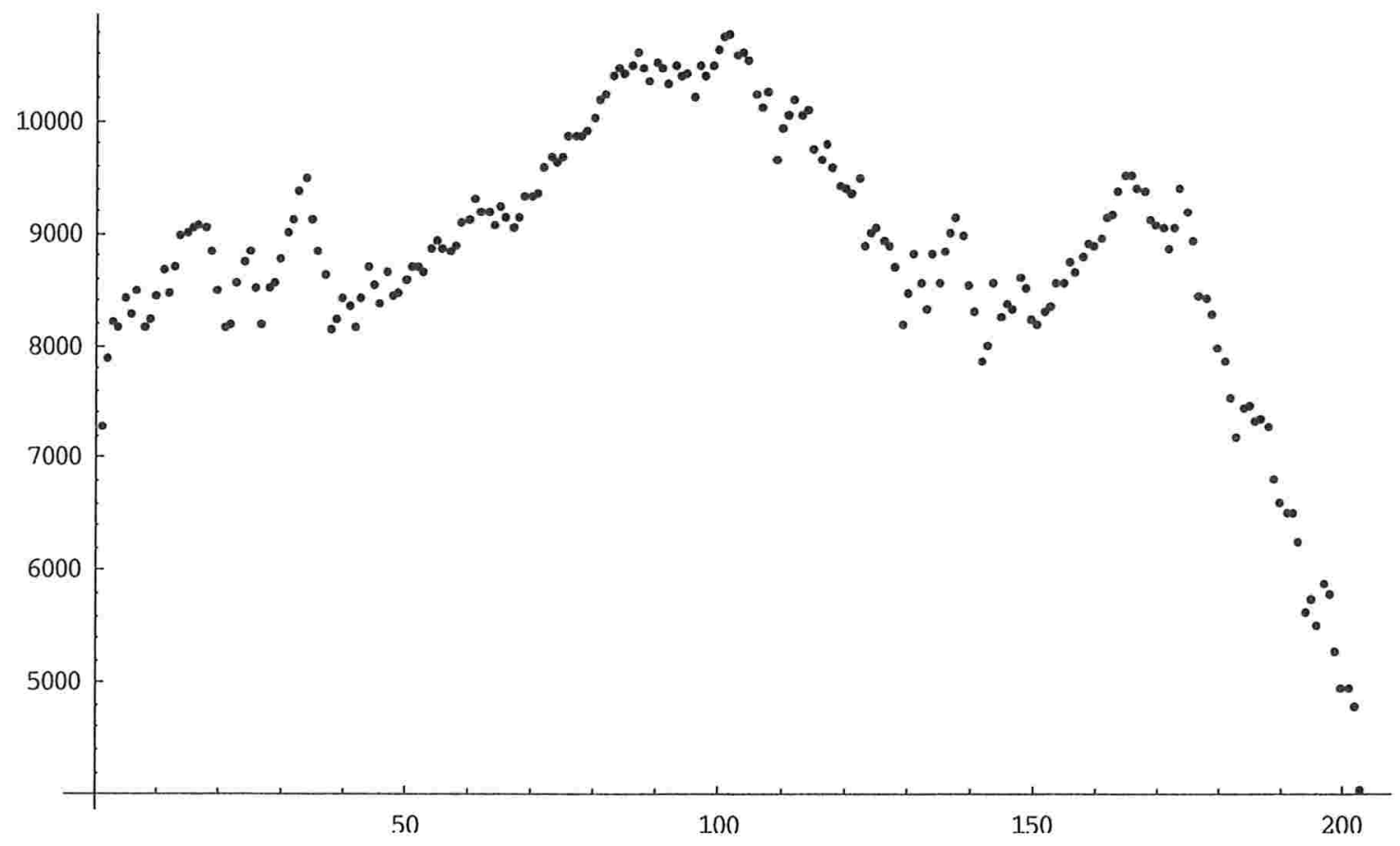


O melhor ajuste conseguido foi:

$$
\begin{aligned}
& A \approx 7,047, B \approx 1,609, t_{c} \approx 198,403, C \approx-0,065, \omega \approx 3,53, \beta \approx 0,00545 \\
& O \text { dado número } 199 \text { da série selecionada refere-se ao dia 03/09/1998 e }
\end{aligned}
$$
representa a data estimada pelo modelo para o inicio do crash de 10/09/1998. Mesmo ajustando com uma diferença de 5 dias úteis da data observada, podemos considerar um bom ajuste, dada a estimação dos demais parâmetros, principalmente de $\omega$, que ficou em 3,53.

O ajuste que encontramos é como mostra o gráfico abaixo:

Gráfico 4.2.2.2: AJUSTE DO MODELO x LOG PREÇO IBOVESPA PARA O PERÍODO - CRISE RUSSA

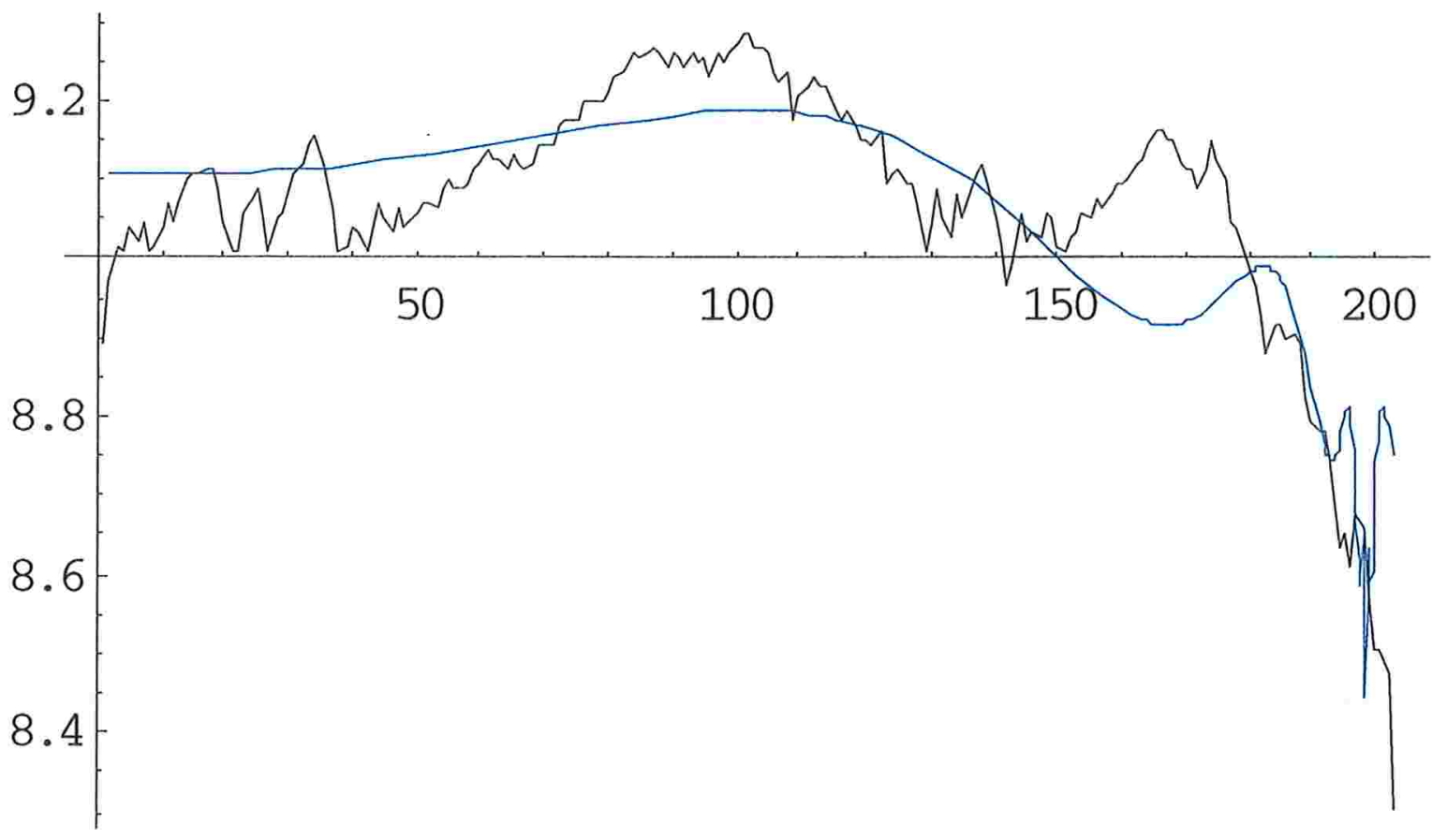

\subsection{3) Crise desvalorização do Real}

Para estimar os parâmetros para a crise originada pela desvalorização cambial brasileira de 1999, foi necessário selecionar os dados de outubro de 1998 até janeiro de 1999, conforme mostra o gráfico abaixo: 
Gráfico 4.2.3.1: CRISE DESVALORIZAÇÃO CAMBIAL BRASILEIRA

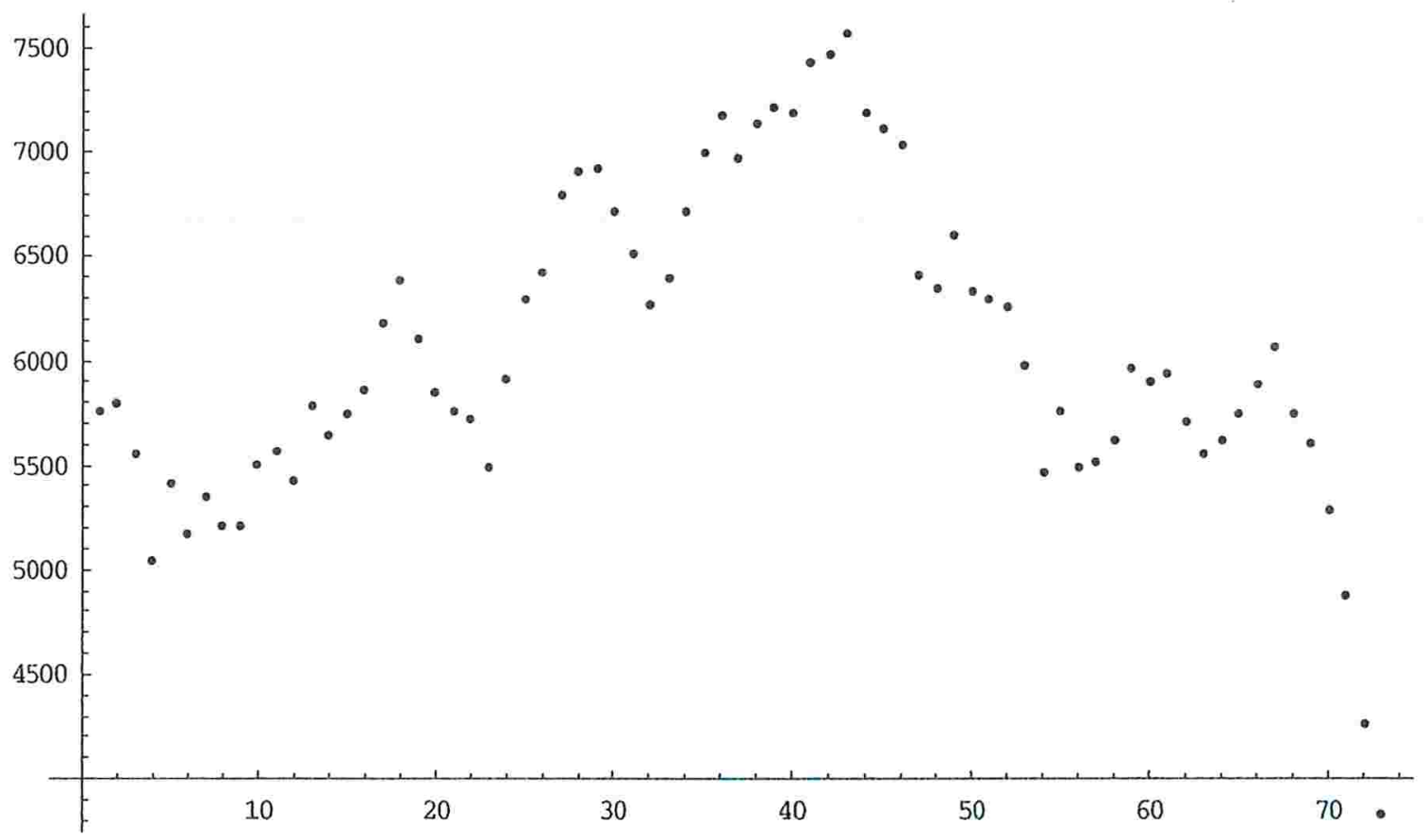

O melhor ajuste conseguido foi:

$A \approx 8,2651, B \approx 0,2708, t_{c} \approx 71,03, C \approx 0,079, \omega \approx 3,762, \beta \approx 0,16$

O dado número 71 da série selecionada refere-se ao dia 11/01/1999, que podemos confrontar com a data observada 13/01/1999. Podemos notar também que $\omega$ ficou alto, assim como nos ajustes anteriores.

O ajuste que encontramos é como mostra o gráfico abaixo:

Gráfico 4.2.3.2: AJUSTE DO MODELO x LOG PREÇO IBOVESPA PARA O PERÍODO - DESV. CAMBIAL

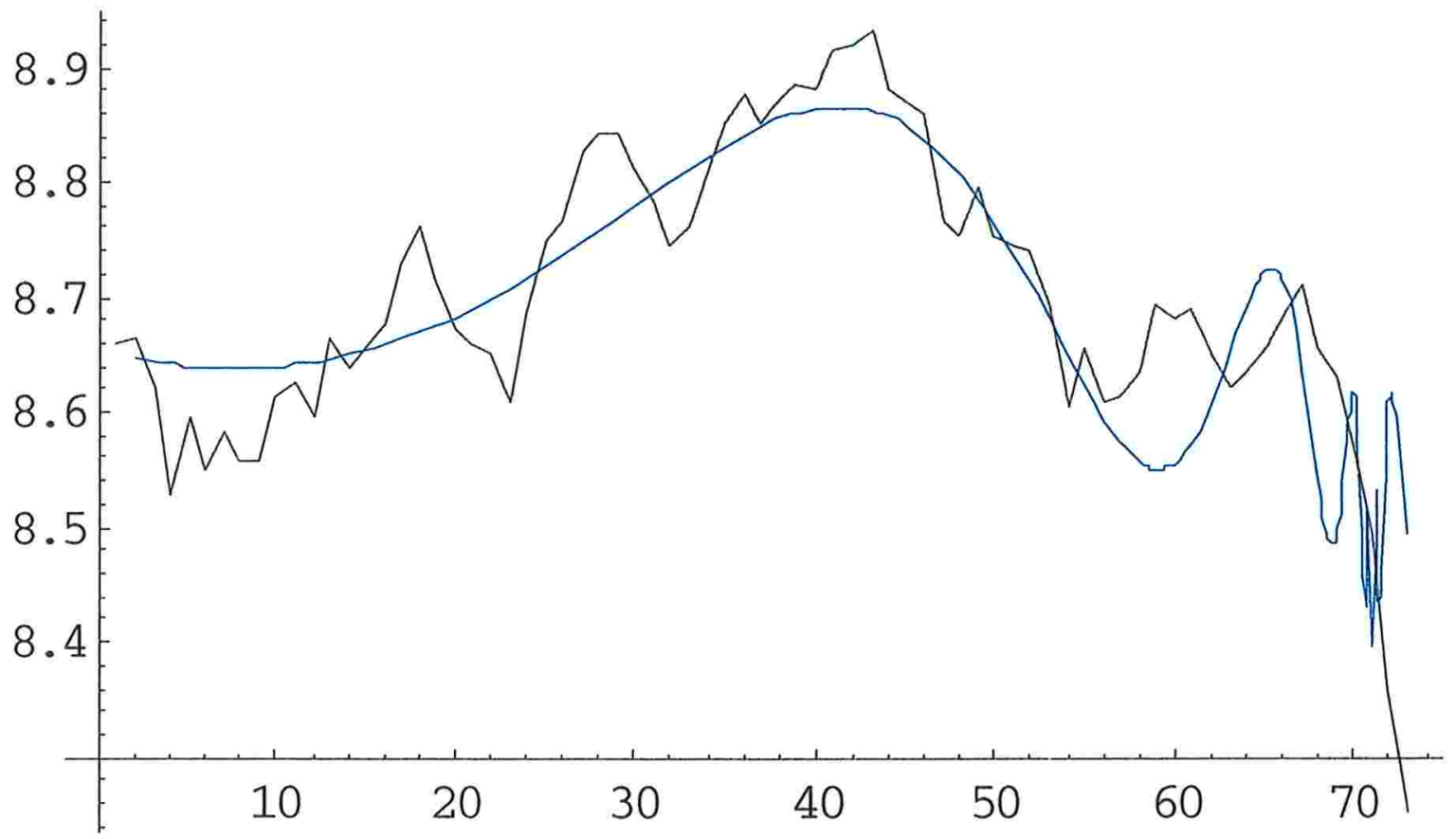


Podemos concluir, portanto, como vimos nos três ajustes apresentados, que é possível aproximar o comportamento dos crashes ocorridos no Brasil na década de 90 através da equação (18).

Se, ainda, selecionarmos uma série de dados do Ibovespa referente a um período onde não há observação de pontos outliers, ou seja, não há constatação de nenhum crash ocorrido e tentarmos proceder com o ajuste, assim como fizemos para as três séries acima, ao analisarmos o comportamento de $\omega$, se este se apresentar baixo estaremos dando maior robustez ao modelo.

Procedi dessa maneira com os dados de 1986, conforme gráfico abaixo, e encontramos $\omega=2,19$, como poderíamos esperar. Podemos notar que não há sinais de movimentos log-periódicos fortes no ajuste que foi feito.

Gráfico 4.2.3.3: AJUSTE DO MODELO x LOG PREÇO IBOVESPA PARA UM PERÍODO SEM PRESENÇA DE CRASHES

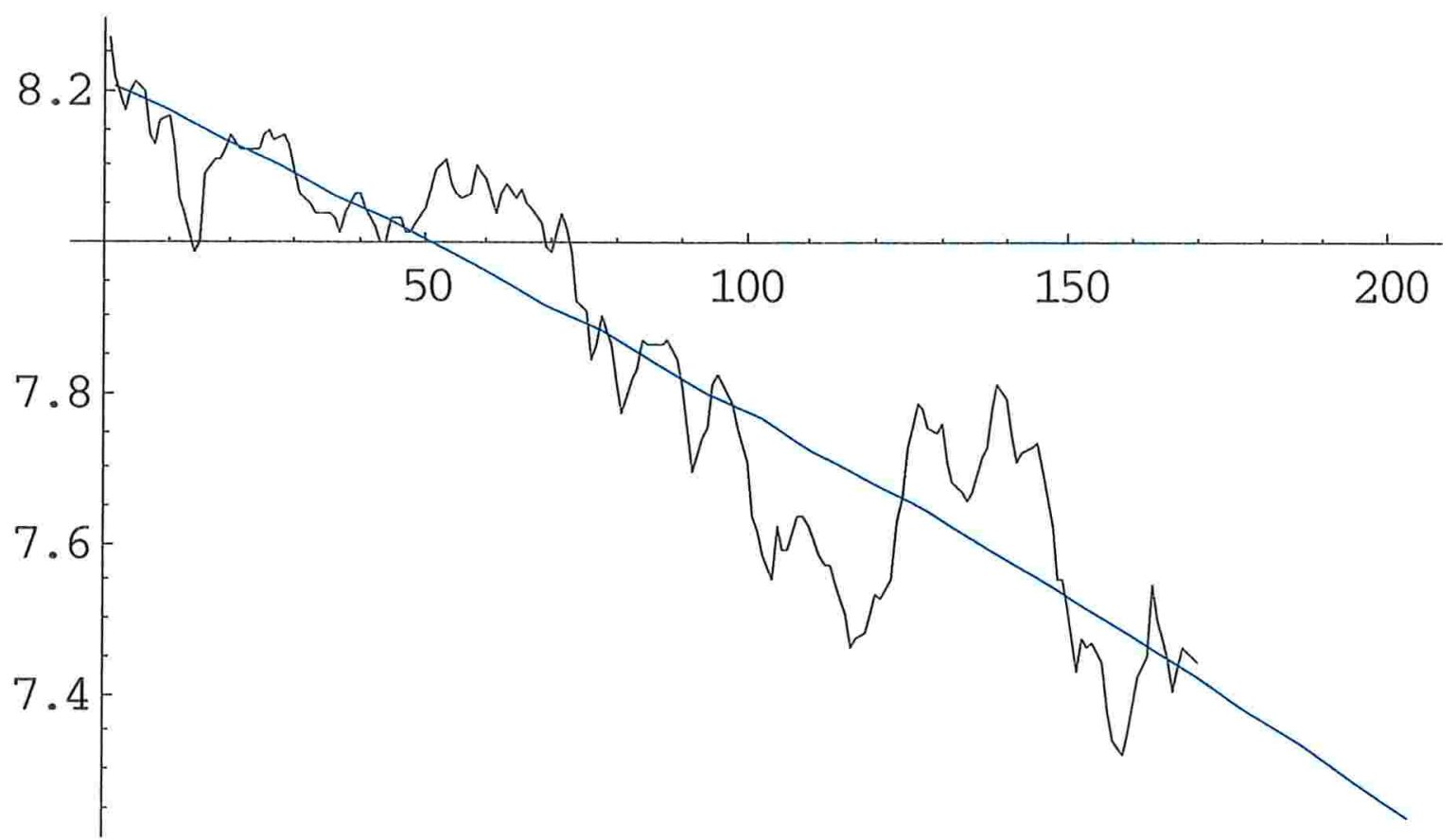




\section{5.) PREVISIBILIDADE}

Uma questão que pode surgir, derivada da análise do modelo, é referente ao poder de previsibilidade que possui a equação (18) e (22).

Quanto tempo anterior a um crash é possivel identificar as evidências de oscilações log-periódicas? A importância de responder a essa pergunta não é somente de medir o poder de previsibilidade do modelo, mas sim, de testar o quão robustos são os resultados obtidos até o momento.

Obviamente, se a estrutura log-periódica dos dados for puramente acidental, o valor dos parâmetros obtidos deveriam depender fortemente do tamanho do intervalo de tempo usado no ajuste do modelo. Para fazer esse teste, é possivel aplicar o seguinte procedimento: Para cada um dos crashes modelados, pode-se remover alguns pontos e reajustar o modelo usando o mesmo procedimento aplicado nas seções anteriores.

Especificamente ao logaritmo do S\&P500, para o crash de 1987, pode-se truncar os dados em 1985 e reajustar o modelo. Posteriormente, deve-se ir acrescentando dados correspondentes a 0,16 anos à série e ajustar o modelo sucessivamente, até que os dados estejam completos novamente. Os resultados obtidos podem ser vistos na tabela abaixo: 
Tabela 5.1: RESULTADOS OBSERVADOS PARA O LOG DO S\&P500 ANTERIOR AO CRASH DE 1987.

\begin{tabular}{|c|c|c|}
\hline Data Final & Pontos mínimos & $t_{c}$ ref aos mínimos \\
\hline 85.00 & 1 & 86.52 \\
\hline 85.14 & 4 & 4 entre 86.7 e 86.8 \\
\hline 85.30 & 7 & 5 entre 86.5 e 87.0 e 2 entre 87.4 e 87.6 \\
\hline 85.46 & 8 & 7 entre 86.6 e $86.9,87.22$ \\
\hline 85.62 & 13 & 12 entre 86.8 e $87.1,87.65$ \\
\hline 85.78 & 7 & $87.48,5$ entre 87.0 e $87.25,87.68$ \\
\hline 85.93 & 4 & $87.25,87.01,87.34,86.80$ \\
\hline 86.09 & 4 & $87.29,87.01,86.98,87.23$ \\
\hline 86.26 & 7 & 5 entre 87.2 e $87.4,86.93,86.91$ \\
\hline 86.41 & 4 & $87.26,87.36,87.87,87.48$ \\
\hline 86.57 & 2 & $87.67,87.34$ \\
\hline 86.73 & 7 & 4 entre 86.8 e $87.0,87.37,87.79,87.89$ \\
\hline 86.88 & 1 & 87.79 \\
\hline 87.04 & 2 & $87.68,88.35$ \\
\hline 87.20 & 2 & $87.79,88.03$ \\
\hline 87.36 & 2 & $88.19,88.30$ \\
\hline 87.52 & 3 & $88.49,87.92,88.10$ \\
\hline 87.65 & 3 & $87.81,88.08,88.04$ \\
\hline
\end{tabular}

Onde a data final está expressa de forma centesimal, ou seja, 86.25 representaria março de 1986.

Na tabela, podemos observar o número de mínimos e os valores de $t_{c}$ encontrados para cada um dos intervalos ajustados. A conclusão que se chega é que um ano ou mais anteriores ao crash, os dados não são suficientes para nos dar nenhuma resposta conclusiva. Aproximadamente 1 ano antes do crash, o ajuste começa a apontar uma data para $t_{c}$ com maior precisão, a qual difere da data real por apenas algumas semanas. 
Podemos ver na tabela abaixo os valores das variáveis $\beta, \omega, \tau$ e verificamos que o modelo torna-se mais robusto à medida que nos distanciamos em 1 ano da data real do crash.

Tabela 5.2: VALORES CALCULADOS PARA $\beta, \omega, \tau$ COM DADOS ATÉ 1 ANO ANTERIOR AO CRASH DE 1987

\begin{tabular}{|c|c|c|c|c|}
\hline Data final & $t_{c}$ & $\beta$ & $\omega$ & $\tau$ \\
\hline 86.88 & 87.79 & 0.66 & 5.4 & 7.8 \\
\hline 87.04 & $87.68,88.35$ & $0.61,0.77$ & $4.1,13.6$ & $12.3,10.2$ \\
\hline 87.20 & $87.79,88.03$ & $0.76,0.77$ & $9.4,11.0$ & $10.0,9.6$ \\
\hline 87.36 & $88.19,88.30$ & $0.66,0.79$ & $7.3,12.2$ & $7.9,8.1$ \\
\hline 87.52 & $88.49,87.92,88.10$ & $0.51,0.71,0.65$ & $12.3,9.6,10.3$ & $10.2,9.8,9.8$ \\
\hline 87.65 & $87.81,88.08,88.04$ & $0.68,0.69,0.67$ & $8.9,10.4,10.1$ & $10.8,9.7,10.2$ \\
\hline
\end{tabular}

Se o objetivo for realmente prever a data do crash, o maior obstáculo será o fato que o procedimento de ajuste usado no modelo gera várias datas possiveis, até mesmo para o intervalo de tempo que possui todos os dados. Como solução, o modelo sugere que se faça a média dos valores encontrados para $t_{c}, \beta, \omega, \tau$, dados os diferentes mínimos.

Tabela 5.3: MÉDIA DOS VALORES CALCULADOS PARA $\beta, \omega, \tau$ COM DADOS ATÉ 1 ANO ANTERIOR AO CRASH DE 1987

\begin{tabular}{|c|c|c|c|c|}
\hline Data final & $t_{c}$ & $\beta$ & $\omega$ & $\tau$ \\
\hline 86.88 & 87.79 & 0.66 & 5.4 & 7.8 \\
\hline 87.04 & 88.02 & 0.69 & 8.6 & 11.3 \\
\hline 87.20 & 87.91 & 0.77 & 10.20 & 9.8 \\
\hline 87.36 & 88.25 & 0.73 & 9.6 & 8.0 \\
\hline 87.52 & 88.17 & 0.62 & 10.7 & 9.9 \\
\hline 87.65 & 87.98 & 0.68 & 9.8 & 10.2 \\
\hline
\end{tabular}


Podemos observar com isso que os valores de $\beta, \omega, \tau$ ficam $20 \%$ diferentes daqueles apontados pela melhor previsão, mas a previsão de $t_{c}$ não melhorou significativamente. A razão para isso é que, geralmente, ajustes acabam causando um 'over-shoot' sobre a previsão do dia verdadeiro do crash.

É possivel aplicar esse procedimento também ao logaritmo do índice Down Jones anteriormente ao crash de 1929. Os resultados obtidos são mostrados na tabela abaixo:

Tabela 5.4: RESULTADOS OBSERVADOS PARA O LOG DO DOWN JONES ANTERIOR AO CRASH DE 1929.

\begin{tabular}{|c|c|c|}
\hline Data Final & Pontos minimos & $\mathrm{t}_{\mathrm{c}}$ ref aos minimos \\
\hline 27.37 & 1 & 31.08 \\
\hline 27.56 & 2 & $30.44,30.85$ \\
\hline 27.75 & 1 & 30.34 \\
\hline 27.94 & 4 & 31.37 \\
\hline 28.13 & 4 & $29.85,30.75,30.72,30.50$ \\
\hline 28.35 & 1 & $30.29,30.47,30.50,30.50$ \\
\hline 28.52 & 1 & 31.30 \\
\hline 28.70 & 4 & 31.02 \\
\hline 28.90 & 2 & $30.40,30.72,31.07,30.94$ \\
\hline 29.09 & 1 & $30.52,30.35$ \\
\hline 29.28 & 3 & 30.61 \\
\hline 29.47 & 1 & $29.91,30.1,29.82$ \\
\hline 29.67 & & 29.87 \\
\hline
\end{tabular}


Tabela 5.5: VALORES CALCULADOS PARA $\beta, \omega, \tau$ COM DADOS ATÉ 1 ANO ANTERIOR AO CRASH DE 1929.

\begin{tabular}{|c|c|c|c|c|}
\hline Data final & $t_{c}$ & $\beta$ & $\omega$ & $\tau$ \\
\hline 28.90 & $30.40,30.72$, & $0.60,0.70,0.70$, & $7.0,7.6,10.2$, & $12.3,9.5,9.0$, \\
& $31.07,30.94$ & 0.53 & 13.7 & 11.6 \\
\hline 29.09 & $30.52,30.35$ & $0.54,0.62$ & $11.0,7.8$ & $12.6,10.2$ \\
\hline 29.28 & 30.61 & 0.63 & 9.5 & 9.5 \\
\hline 29.47 & $29.91,30.1,29.82$ & $0.60,0.67,0.69$ & $5.8,6.2,4.5$ & $15.9,11.0,10.9$ \\
\hline 29.67 & 29.87 & 0.61 & 5.4 & 15.0 \\
\hline
\end{tabular}

Tabela 5.5: MÉDIA DOS VALORES CALCULADOS PARA $\beta, \omega, \tau$ COM DADOS ATÉ 1 ANO ANTERIOR AO CRASH DE 1929

\begin{tabular}{|c|c|c|c|c|}
\hline Data final & $t_{c}$ & $\beta$ & $\omega$ & $\tau$ \\
\hline 28.90 & 30.78 & 0.63 & 9.6 & 10.6 \\
\hline 29.09 & 30.44 & 0.58 & 9.4 & 11.4 \\
\hline 29.28 & 30.61 & 0.63 & 9.5 & 9.5 \\
\hline 29.47 & 29.94 & 0.65 & 5.5 & 12.6 \\
\hline 29.67 & 29.87 & 0.61 & 5.4 & 15.0 \\
\hline
\end{tabular}

Observamos que foi preciso estar a 4

quatro meses do crash para o ajuste que apontasse uma data bem próxima da data real e, a partir de então, tivesse um comportamento igual ao resultados obtidos com os dados completos referentes ao crash de 1987. O fato desses dados se ajustarem proporcionalmente depois é devido a diferença no tempo de transição $\Delta_{t}$ que existe nos dois casos, o que significa que o indice Down Jones, anterior ao crash de 1929, exibiu menos oscilações distintas.

Desse procedimento, o que podemos observar é que existe uma tendência, nos dois casos, de haver um 'over-shoot' de $t_{c}$, ou seja, mesmo que $\beta, \omega, \tau$ permaneçam perto de seus valores obtidos quando foi trabalhado o intervalo de 
tempo inteiro, o ajuste começa a superestimar $t_{c}$. A razão para isso pode ser encontrada no próprio modelo, ou seja, a diferença que existe entre a equação (12), que representa uma lei de potência pura e as equações (18) e (22) é que essas últimas não mais só dependem do expoente crítico $\beta$, mas sim, também das freqüências $\omega e \Delta_{w}$. Sendo assim, ao truncar o intervalo de tempo, remove-se parte da oscilação, prejudicando a determinação de $\omega e \Delta_{w}$, e por conseqüência $t_{c}$.

O fenômeno do 'over-shoot' pode ser considerado consistente com a teoria, ou seja, totalmente de acordo com o modelo de expectativas racionais dos crashes, uma vez que a ocorrência de crashes é um fenômeno aleatório que ocorre com uma probabilidade que aumenta conforme nos aproximamos de $t_{c}$. Portanto, podemos esperar que o modelo ajustado nos dê valores para $t_{c}$ muito próximos da data real, mas sistematicamente depois.

\section{1) Alarmes falsos}

Nem todas as bolhas especulativas terminam em um crash, conforme vimos nas seçōes anteriores. Empiricamente, o modelo, por duas vezes, já identificou bolhas com comportamentos semelhantes a uma lei de potência com oscilaçōes logperiódicas, sinalizando um crash, mas que de fato não ocorreram.

A primeira constatação foi a perturbação no mercado financeiro dos EUA em 1997 que se ajustou ao modelo quando foi possivel detectar uma estrutura logperiódica e prever tal perturbação no mercado de ações norte americano para o final de outubro de 1997, ( ex ante 17 de setembro de 1997).

O que acabou acontecendo foi que o crash não ocorreu, apenas um dia com grandes quedas nos preços e altas volatilidades, sem dúvida, o dia mais nervoso no mercado depois do crash de 1987.

A Segunda constatação foi referente a perturbação causada pelo discurso de Alan Greenspan em Outubro de 1999 quando o indice Down Jones atingiu, pela primeira vez, depois de Abril de 1999, cotação abaixo de 10.000 pontos. No entanto, não ocorreu um crash no mercado, que se recuperou rapidamente. 
Tais fatos não devem ser explicados como falha da teoria e sim, consistente com o modelo racional do crash conforme, foi exposto por todo o trabalho. Essas constataçōes acabam por ilustrar a dificuldade envolvendo a previsibilidade dos crashes usando as equaçōes (18) e (22), pois, de acordo com a teoria, $t_{c}$ não é necessariamente o momento do crash, mas sim seu momento mais provável. Isso, se adicionarmos o fato de que a bolha se expande até um ponto em que o crash torna-se cada vez mais previsível e os preços passam a desenvolver estruturas características, o $t_{c}$ pode passar sem que um crash ocorra. Isso corresponde a uma probabilidade finita $1-Q\left(t_{c}\right)$, conforme já definido, que nenhum crash aconteça durante todo o tempo, incluindo $t_{c}$ até o final da bolha. 


\section{6.) CONCLUSÃO}

Esse trabalho apresentou uma teoria que faz uma conexão entre crashes no mercado de ações e o comportamento crítico de sistemas complexos e como as características desses sistemas podem influenciar os preços até mesmo quando o mercado è racional.

A teoria que foi apresentada sustenta ainda, e é uma hipótese básica do modelo, que a imitação local de comportamento entre os traders pode se propagar através de escalas e causar os crashes. Ainda podemos somar a isso as evidências de que os crashes são pontos outliers na distribuição de draw downs, o que resulta, como conseqüência, que os crashes possuem sua origem em um fenômeno. Para esse fenômeno atribuímos um comportamento log-periódico descrito pelas equações (18) e (22).

O modelo já foi testado para três grandes crashes desse século, onde foi possivel identificar tal comportamento, o crash de 1929, 1987 da bolsa de Nova Iorque e 1997 em Hong Kong.

Adicionado a isso, o período que precedeu as perturbações ocorridas em Outubro de 1997 e Outubro de 1999 apresentaram também valores de parâmetros consistentes com os dos outras três crashes, ou seja, estruturas log-periódicas que levavam a estimação de $t_{c}$ para essas datas. Os crashes não ocorreram, mas devem ser interpretados como realizações compatíveis com a teoria das expectativas racionais de crashes, que nos indica que existe uma probabilidade não nula de que nenhum crash ocorra, mesmo sob condições de crescimento de bolhas.

No ensaio feito para os crashes ocorridos no mercado acionário brasileiro durante a década de 90 , também identificamos um comportamento log-periódico onde a estimação de $\omega$, através da equação (18), ficou superior a 3,5 para os 3 ajustes realizados, levando a estimação dos $t_{c}$ bem próximos das datas observadas.

Ainda para que fosse possivel testar a robustez dos resultados encontrados, estimamos o parâmetro $\omega$ para um período onde não houve observação de pontos outliers, ou seja, ocorrência de crashes, e pudemos notar que seu valor ficou bem abaixo dos encontrados anteriormente, como poderíamos esperar. 
O modelo também nos permite testar a habilidade de previsibilidade através da equação (22). O procedimento apresentado, no entanto, tende a causar um 'overshoot' 'na previsão da data dos crashes. Tal fato também é totalmente consistente com o modelo apresentado, uma vez que $t_{c}$ é o momento mais provável de ocorrência do crash, que deve ocorrer, se ocorrer, perto de, mas anterior a $t_{c}$.Tal procedimento não foi testado para os crashes ocorridos no Brasil, neste trabalho.

Essa questão fundamental sobre o uso do modelo para prever próximos crashes deve ainda conviver com a reação dos agentes frente ao fato, ou seja, existem três cenários possiveis que podem ocorrer:

1. Ninguém acredita que a previsāo é correta e o mercado sofrerá, portanto, um crash;

2. Todos acreditam na previsão, causando pânico, e o mercado sofrerá o crash;

3. Todos acreditam que a previsão pode estar correta e o mercado acomodase, mudando sua tendência, fazendo com que o crash não ocorra;

Nenhum desses cenários são atrativos, visto que nos dois primeiros o crash ocorre e no terceiro a previsão se auto-destrói, ou seja, a implementação de tais modelos na sociedade implica em considerações muito mais complexas.

Como foi apresentado por todo o trabalho, o modelo enfatiza o comportamento coletivo dos agentes que podem levar o mercado a momentos de instabilidade causando crashes. Isso deve ser contrastado imediatamente com o estudo de analistas e estudiosos do mercado que estāo sempre à procura de notícias contemporâneas e fatos para explicar tais eventos.

O crash de Agosto de 1998, por exemplo, foi atribuído à desvalorização do rublo e a moratória russa. Não podemos, de forma nenhuma, ignorar tais fatos, mas não podemos deixar de salientar que o mercado é constantemente bombardeado por tais notícias e sempre será possivel atribuí-los à um crash, ex post. 


\section{7.) REFERÊNCIAS BIBLIOGRÁFICAS}

Johansen, A . \& Sornette,D. (1999). Critical crashes. Risk, Vol 12, No. 1, p.91-94 (1999). http://xxx.if.usp.br/ps/cond-mat/9901035.

Johansen, A . \& Sornette,D. (2000). The Nasdaq crash of April 2000: Yet another example of log-periodicity in a speculative bubble ending in a crash. European Physical Journal B 17, 319-328 (2000). http://xxx.if.usp.br/ps/cond-mat/0004263.

Johansen, A . \& Sornette,D. (1999). Modeling the Stock Market prior to large crashes. Eur. Phys. J. B 9, pp. 167-174 (1999). http://xxx.if.usp.br/ps/cond-mat/9811066.

Johansen, A ., Ledoit, O. \& Sornette, D. (1998). Crashes as Critical Points. Int. J. Theor. Applied Finance, Vol 3 No 1 (January 2000). http://xxx.if.usp.br/ps/condmat/9810071.

Johansen, A ., Sornette, D \& Ledoit, O. (1999). Predicting Crashes Using Discrete Scale Invariance. Journal of Risk, Vol 1, No. 4 (1999) 5-32. http://xxx.if.usp.br/ps/cond-mat/9903321.

Johansen, A . \& Sornette,D. (2000). Log-periodic power law bubbles in Latin-American and Asian markets and correlated anti-bubbles in Western stock markets: An emprircal study. http://xxx.if.usp.br/ps/cond-mat/9907270.

Johansen, A . \& Sornette,D. (2001). Significance of log-periodic precursors to financial crashes. Quantitative Finance 1 (4), 452-471 (2001). http://xxx.if.usp.br/ps/condmat/0106520.

Malkiel, B. G. (1999). A Random Walk Down Wall Street, Capítulo II, páginas 35-53, Norton, EUA.

Sornette, D \& Johansen, A . (1997). Large financial crashes. Physica A 245, 411-422 (1997). http://xxx.if.usp.br/ps/cond-mat/9704127. 